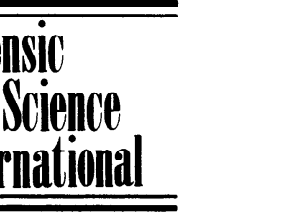

\title{
Advances in capillary electrophoresis
}

\author{
Zdeněk Deyl $^{\mathrm{a}, \mathrm{b}, *}$, Ivan Mikšík ${ }^{\mathrm{a}}, \mathrm{F}$. Tagliaro ${ }^{\mathrm{c}}$ \\ ${ }^{a}$ Institute of Physiology, Academy of Sciences of the Czech Republic, Vídeñská 1083, CZ 14220 Prague \\ 4, Czech Republic \\ ${ }^{\mathrm{b}}$ Dept. Anal. Chem., Institute of Chemical Technology, Technická 1905, CZ 16628 Prague 6, Czech \\ Republic \\ ${ }^{\mathrm{c}}$ Institute of Forensic Medicine, University of Verona, Verona, Italy
}

\begin{abstract}
This review summarizes the advancement in operational modes and selected applications of the title technique over the past five years. Regarding operational modes particular emphasis is put upon increasing selectivity and resolution, hyphenation of capillary electrophoresis with techniques based on other than electromigration principles, the so-called chip technology and new ways of detection. In applications selected examples of chiral separations and separation of biopolymers (proteins, nucleic acids) are emphasized. It is demonstrated that capillary electrophoresis represents a complementary technique to high-performance column chromatography and in a number of cases it offers better separations than standard chromatographic procedures. (C) 1998 Elsevier Science Ireland Ltd.
\end{abstract}

Keywords: Capillary electrophoresis - Review; Increasing selectivity and resolution; Chiral separations

\section{Introduction}

Capillary electrophoresis in its different versions represents a powerful separation technique which proved sufficiently competitive/complementary to high performance liquid chromatography. Based on the simultaneous action of electromigration and electroosmotic flow (for principle see Fig. 1) this approach offers a wide range of conditions under which successful separations and quantitations can be obtained. While the "classical" version is limited to charged water soluble analytes only, the discovery of Terabe et al. [1] who introduced micellar systems offered the possibility of separating uncharged analytes on the basis of their partition between a micellar phase and the aqueous background electrolyte. Consequently the potentials of this methodology have

\footnotetext{
*Corresponding author. Tel: +420 2 4752558; fax: +42024752558
} 


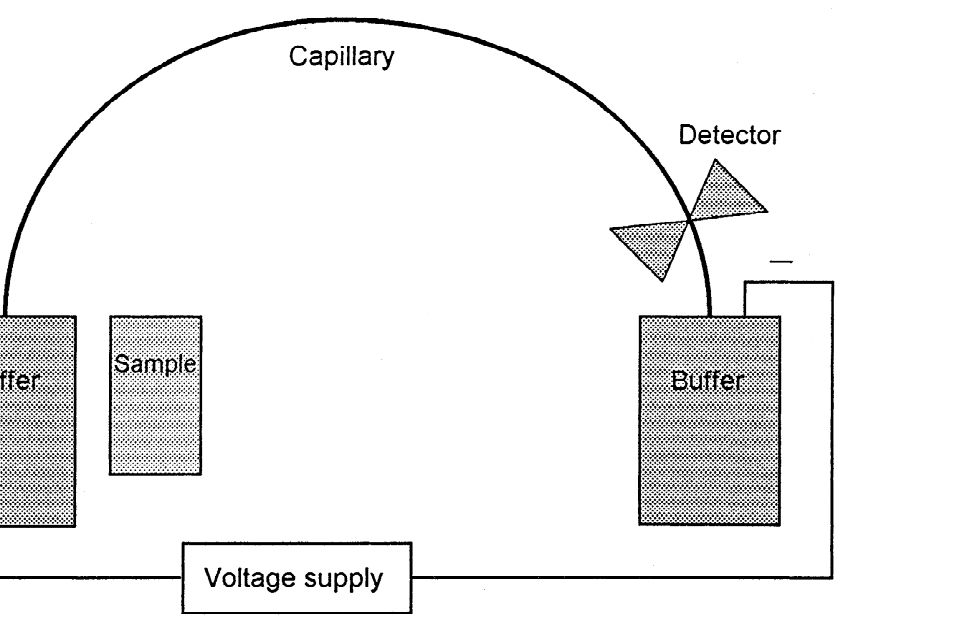

Fig. 1. Schematic drawing of capillary electrophoresis instrumentation. Upon applying voltage on the capillary separation occurs according to the electric charge anions migrating to anode, cations to cathode. In addition there is a strong endoosmotic flow which moves the whole content of the capillary from anode to cathode (in most cases); consequently cations move ahead of the endoosmotic flow, anions move behind it.

spread to all kinds of non-polar solutes. As the principles of the different modes have been reviewed many times in the past (see, e.g., [2-6]), in the present review we shall emphasize the recent advances of this technique only with particular attention to categories of compounds that might be of forensic importance. Rather than reviewing topical examples, which frankly saying are not too many so far, we shall limit ourselves to the description of how individual categories of compounds may be treated by this technique. Because in forensic science we are nearly always faced with complex natural samples in the most diverse biological matrices a need for a confirmatory step is badly needed. This is usually solved by hyphenating the capillary electrophoretic separation with a method based on another physico-chemical principle, most frequently MS; however, other approaches like NMR, spectrometry and spectrofluorometry can be exploited as well depending on the nature of a particular case.

\section{Progress in operational modes}

\subsection{Advances in pseudostationary phases for micellar electrokinetic chromatography}

While pseudostationary phases of the SDS type and quaternary ammonium bases have become a routine in capillary electrophoretic separations of compounds poorly soluble in water, it is foreseen that by modifying the nature of the micelles (or hydrophobized sorbents in the case of capillary electrochromatography) can widen the possibilities of capillary separations even further. Partial success has been achieved by increasing the partition of hydrophobic compounds in the aqueous phase [7-15]. Addition of 
cyclodextrins frequently helps the separation however adds complexity and makes the interpretation more difficult. Addition of organic solvents has also limitations with respect to stability of micelles [16]. A number of reports deal with polymeric pseudostationary phases [17-20]. Polymeric pseudostationary phases for electrokinetic chromatography can be prepared either by polymerizing the micelle structure or by the derivatization of a polymeric support. By exploiting the former approach, Palmer et al. [18,21] and Wang and Warner [22] showed the applicability of micelle polymers prepared from monomers containing undecenyl or undecanoyl functionality. Such phases yield good separations with a wide range of hydrophobic solutes and can be used for chiral separations as well. However, their preparation and purification are rather complicated and, mainly, these pseudostationary phases are so far not commercially available. The other alternative is offered by polyvinylpyrrolidone-based pseudostationary phases [23] and commercially available polymers consisting of methacrylic acid and alkyl methacrylate copolymers [24-27].

The second approach for the preparation of polymeric pseudostationary phases includes the attachment of interacting groups (alkyls or ionic groups) to a polymer support such as starburst dendrimers. This approach is versatile within broad limits because the alkyl groups can be either long or short and can be attached to the support within a wide density range. On the other hand the problems faced here are the slow and/or incomplete reactions of the polymeric structure. A successful approach of this type was reported in refs. [28] and [29] in which modification of starburst dendrimers with alkyl groups is described that allows the use the full range of water-methanol mixtures. The starburst dendrimer-supported pseudostationary phase with attached dodecyl groups showed similar selectivity as the SDS micellar systems in aqueous systems and a higher selectivity with hydrophobic analytes like polyaromatic hydrocarbons in water-methanol mixtures. In spite of the wide potential of such pseudostationary phases, however, their practicability is rather limited owing to the complex way of their preparation. Naturally other polymeric supports can be used (see cf. the use of polyallyl amine for this purpose, [16], Fig. 2)

With some categories of compounds, typically with steroids [30] the separations with a common type of the pseudostationary phase like SDS may be unsatisfactory; in such cases there are a number of ways to success: it is possible to use another surfactant (bile salts, zwitterionic species) (i), to use mixed micelles (ii) composed of two surfactants or a surfactant and an organic modifier or, finally (iii) to use the addition of the organic modifier to the background electrolyte [31,32]. Separation of unsaturated fatty acids and related isomeric hydroperoxides as published recently by Schmitz and Gäb [33] represents a typical example of using two-component micellar pseudophase (Brij and SDS) (Fig. 3).

At the end of this paragraph it is necessary to emphasize that reports dealing with electrophoretic separations of hydrophobic compounds in which a high proportion of the organic modifier in the background electrolyte (up to $8 \%$ of e.g. methanol) combined with a small proportion of the surfactant has been successfully applied has recently appeared. The paper of Kiessig and Vogt [34] about the separation of carnitine and several acyl carnitines represents a typical example (Fig. 4).

Particularly with partly charged analytes the selectivity of the micellar pseudophase 

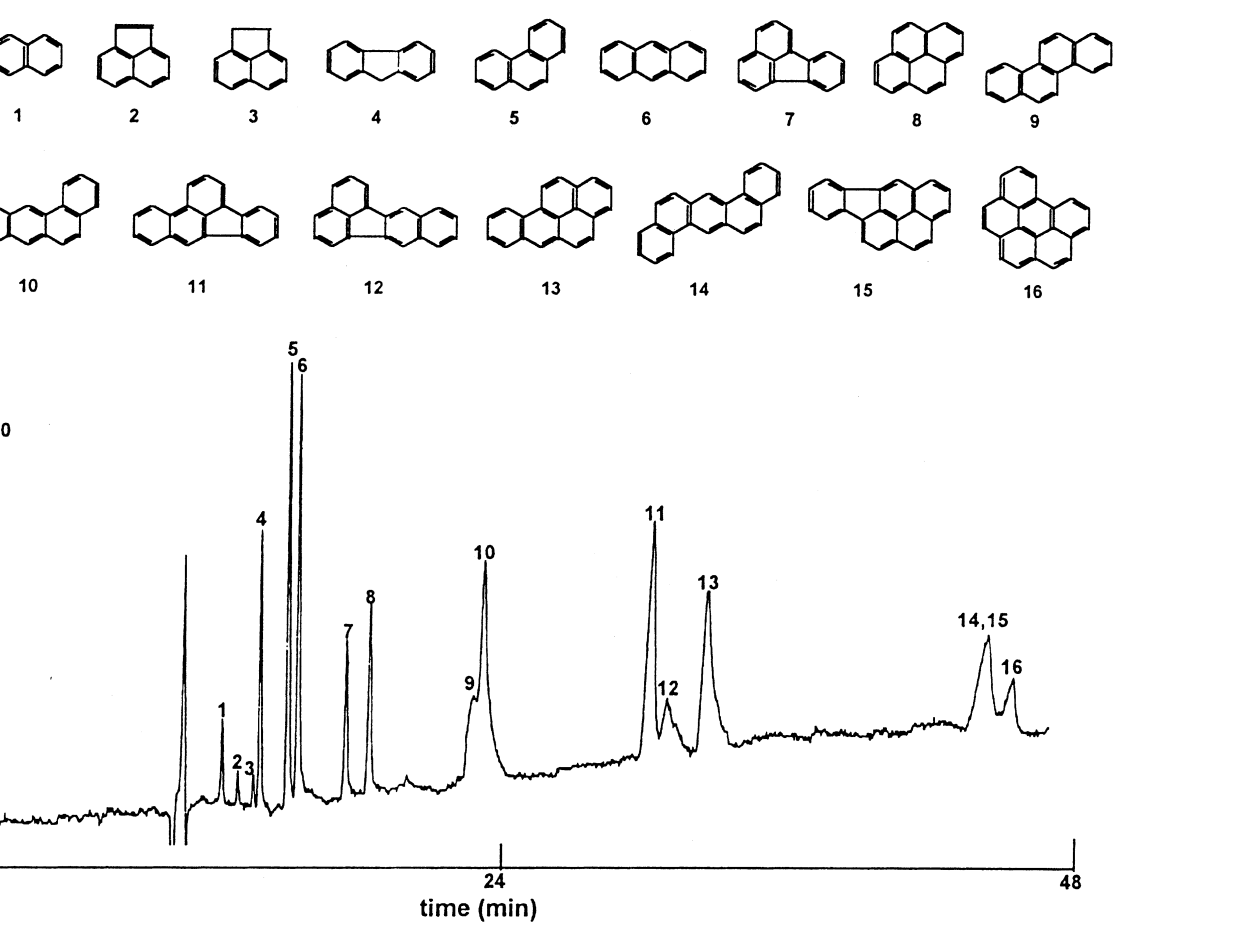

Fig. 2. Separation of $16 \mathrm{PAHs,}$, priority pollutants designed, polyallylamine pseudostationary phase, $\mathrm{C}_{10}$ modified. Borate buffer $(20 \mathrm{mM})$-methanol, 50:50. Field strength-400 V cm${ }^{-1}$. Carrier-20 mg ml ${ }^{-1}$. Separation solution-20 mM borate buffer-methanol mixture. Reproduced with permission from Ref. [16].

can be altered by altering the charged functionality of the micelle, i.e. by using surfactants with e.g. carboxylate, sulphonate or sulphate groupings [35].

\subsection{Background electrolyte gradients}

A number of separations in capillary electrophoresis is done by using e.g. $\mathrm{pH}$ or flow gradients, or in the micellar electrokinetic separation mode by using organic modifier gradients [36,37]. However, most previous work on gradient separation in capillary electrophoretic separations has dealt with $\mathrm{pH}$ gradients. Foret et al. [38] generated a stepped gradient by altering the $\mathrm{pH}$ within the inlet vial and optimized in this way the separation of proteins in a polymer coated capillary. A system using two pumps to control mixing of two background electrolytes has been described by Tsuda [39]. Chang and Yeung [36] used a similar approach to generate dynamic $\mathrm{pH}$ gradients in the range from 3.0 to 5.2 or flow gradients by addition of a cationic surfactant. Also electroosmotic flow pumping has been exploited for gradient formation [40,41]. The main disadvantage of all these approaches is the need of using a custom made equipment which is difficult to mount into a commercially available apparatus.

To circumvent this problem, Whang and Yeung [42] used an electrolyte buffer with a 


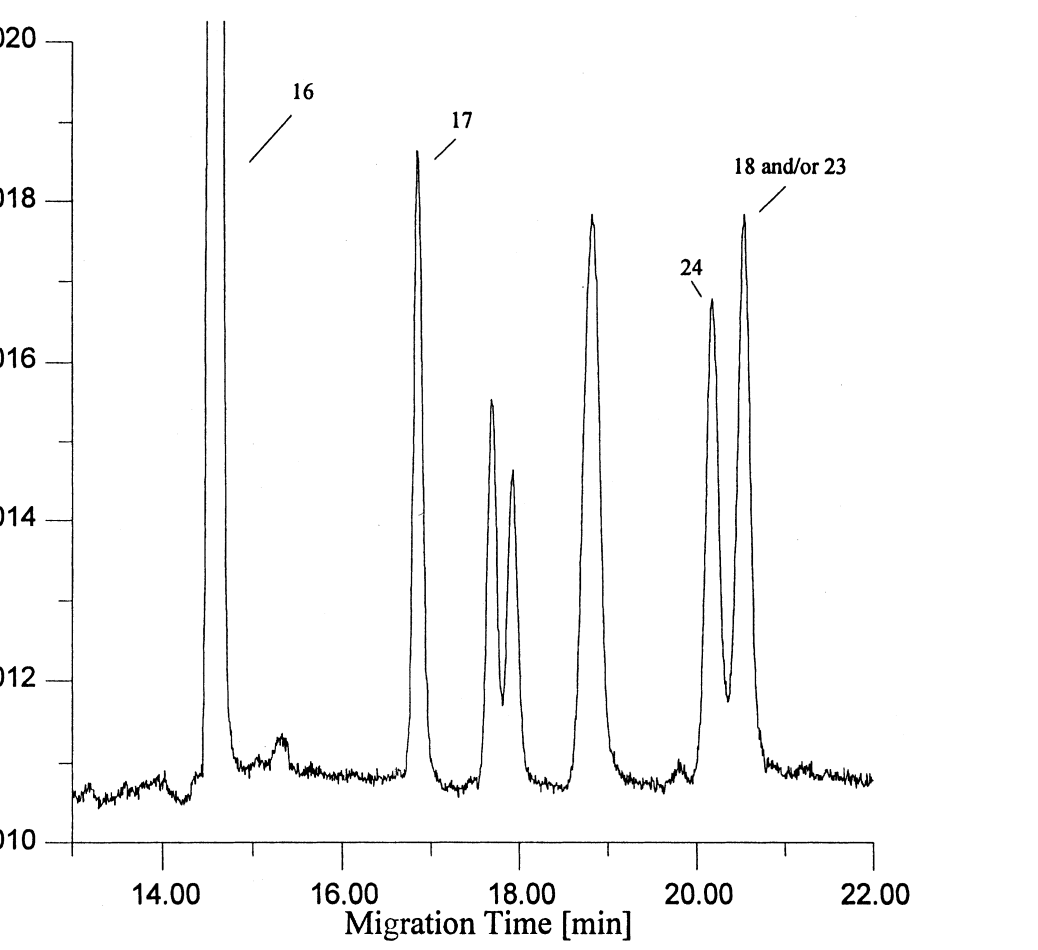

Fig. 3. Separation of arachidonic acid (16) and isomeric hydroperoxides (17-24). Electrolyte: 70\% sodium phosphate (60 mM, pH 6.3), 30\% ethanol, $800 \mathrm{mg} \mathrm{ml}^{-1}$ Brij 35 and $35 \mathrm{mM}$ SDS. Capillary: $40 / 47 \mathrm{~cm} \times 50$ $\mu \mathrm{m}$ uncoated fused-silica. Reproduced with permission from Ref. [33].

large temperature coefficient for materializing $\mathrm{pH}$ gradients: the $\mathrm{pH}$ gradient is generated by altering the temperature of the buffer which is materialized either by changing the temperature of the external circulating coolant or by exploiting Joule heating in the capillary. In practice the buffers used are based on Tris; the approach, no matter how ingenious it is, is limited to buffers possessing large temperature coefficient which is a severe limitation.

Perhaps, the most simple way of introducing any gradient into the capillary electrophoresis system is the dynamic way (called dynamic pulse by Boèek et al. [43]) and close in principle to the electrophoretically mediated microanalysis (EMMA) techniques. Briefly, a short segment of the other buffer component is injected into the capillary [44] (Fig. 5).

\subsection{Methods for resolution enhancement}

Several attempts have been reported in the past to enhance resolution in capillary electrophoresis by controlling the electroosmotic flow. Application of an external field appears one of the possibilities [45-48]. Several limitations, however, are involved in 


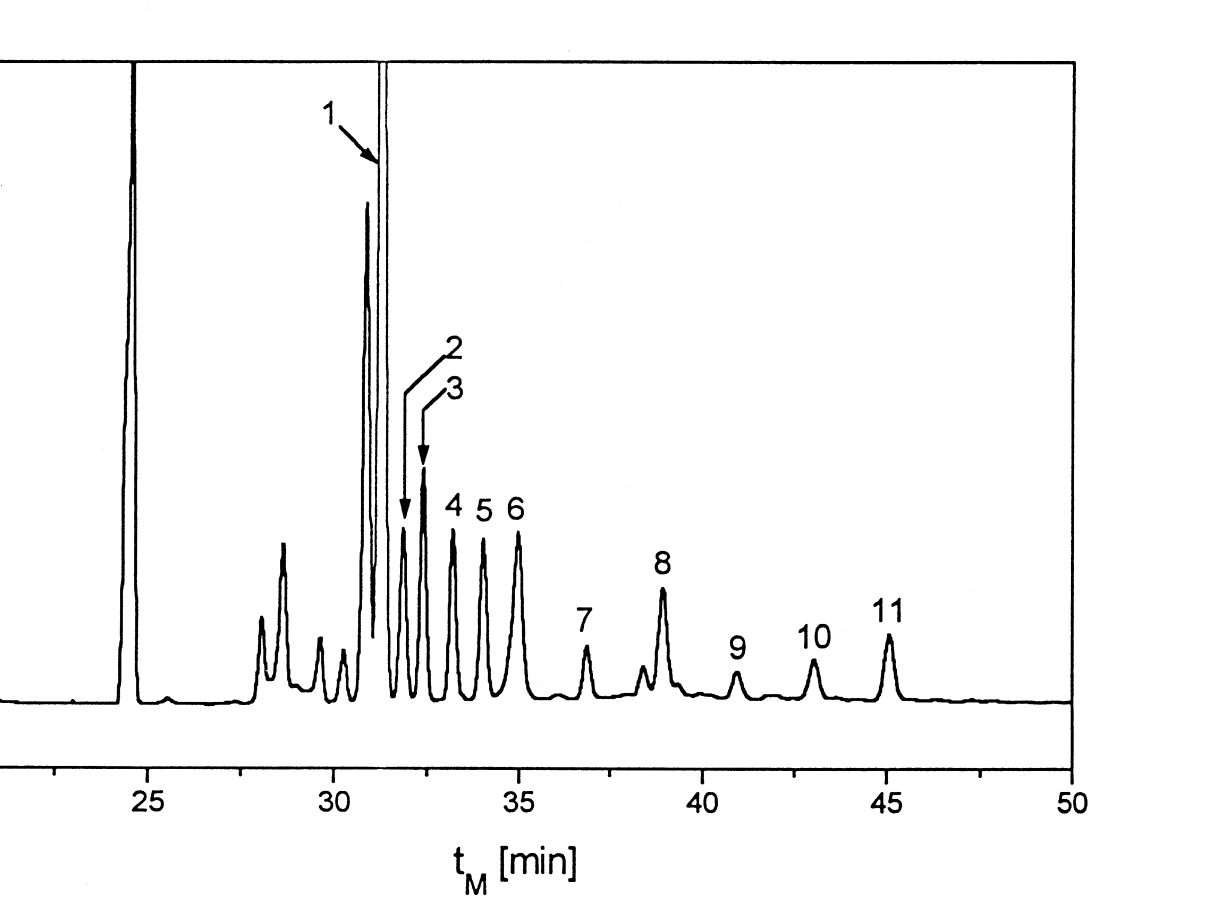

Fig. 4. Separation of carnitine and acylcarnitines. Conditions: injection-30 s electrokinetic at $10 \mathrm{kV}$; separation- $28 \mathrm{kV}, 23^{\circ} \mathrm{C}$; buffer: $88 \%$ methanol, $8 \%$ of a $5 \%$ SDS solution, $4 \%$ of a $85 \%$ phosphoric acid; capillary: $70 / 77 \mathrm{~cm} \times 50 \mu \mathrm{m}$. Identification: 1-carnitine, 2-acetylcarnitine, 3-propionylcarnitine, 4-butyrylcarnitine, 5-valerylcarnitine, 6-hexylcarnitine, 7-octylcarnitine, 8-decylcarnitine, 9-dodecylcarnitine, 10-tetradecylcarnitine and 11-palmitoylcarnitine. Reproduced with permission from Ref. [34].

this approach, namely the dependence of flow on the $\mathrm{pH}$ value, buffer concentration, the external voltages applied and the diameter of the capillary.

Culbertson and Jorgenson [49] selected a different approach by utilizing a pressureinduced flow to counterbalance analyte migration. The pressure was applied at one end of the capillary to retard, halt or move the analytes back and forth the detector's window. In this manner a substantial increase in efficiency and the resolving power was obtained. In short the system helped the analytes to remain in the separation field much longer than in the classical arrangement (called "linear capillary electrophoresis setup"). It is worth mentioning that the above authors were capable of resolving compounds that differed in their electrophoretic mobility as little as $1.10^{-7} \mathrm{~cm}^{2} \mathrm{~s}^{-1}$. The need of precise timing of the pressure application to the capillary end and subsequent broadening of individual peaks caused by the parabolic flow induced by pressurization is considered a serious disadvantage of this approach.

Another procedure has been presented for ion separations using the concept of repeated column switching with synchronized cyclic capillary electrophoresis on a planar microstructure [50]. Micellar electrokinetic separations were also performed with this equipment [51]. 
A) Rinse capillary with primary buffer

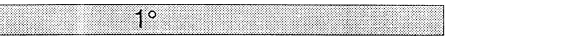

B) Inject pulse of secondary buffer at inlet.

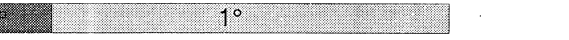

C) Inject sample at inlet.

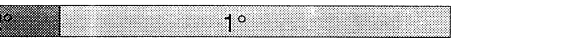

D) Apply voltage to perform electrophoretic separation.

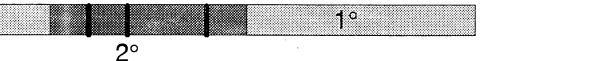

Fig. 5. Schematic representation of a procedure to generate a $\mathrm{pH}$ gradient using a dynamic pulse: (A) Capillary rinsed with primary buffer $\left(1^{\circ}\right)$; (B) secondary buffer $\left(2^{\circ}\right)$ injected hydrodynamically; (C) analytes injected hydrodynamically; and D) electrophoretic separation. Reproduced with permission from Ref. [44].

Choi et al. [52] have quite recently reported another way of solving the same problem; in this arrangement the capillary ends are joined together to form a closed loop in which two electrodes are located so that the flow resistance in the clockwise manner differs from that in the counterclockwise direction. If voltage is applied, electroosmosis causes the sample to circulate inside the capillary. If at least some separation of the analytes involved occurs on a single cycle base on electromigration and/or electrochromatography, then the device (called by the authors electrophoretron) enhances the separation in each cycle performed. Fig. 6 presents a schematic view of the apparatus and Fig. 7 supplies an idea about the course of separation of two analytes upon repeated circles.

\subsection{Capillary electrochromatography}

Though the principle of this technique is quite old [53,54] it is only recently when it became more widely applied in practice [55]. The key feature in capillary electrochromatography (CEC) is the generation of endosmotic flow upon application of high voltage across a packed capillary column. When sample is applied its separation occurs on the basis of two mechanisms which may be involved separately or in combination, namely partition between the mobile and stationary phase (comparable to e.g. reversedphase chromatography) and differences in charge (electrophoretic mechanism). Capillary electrochromatography is applicable to the analysis of both neutral and charged 


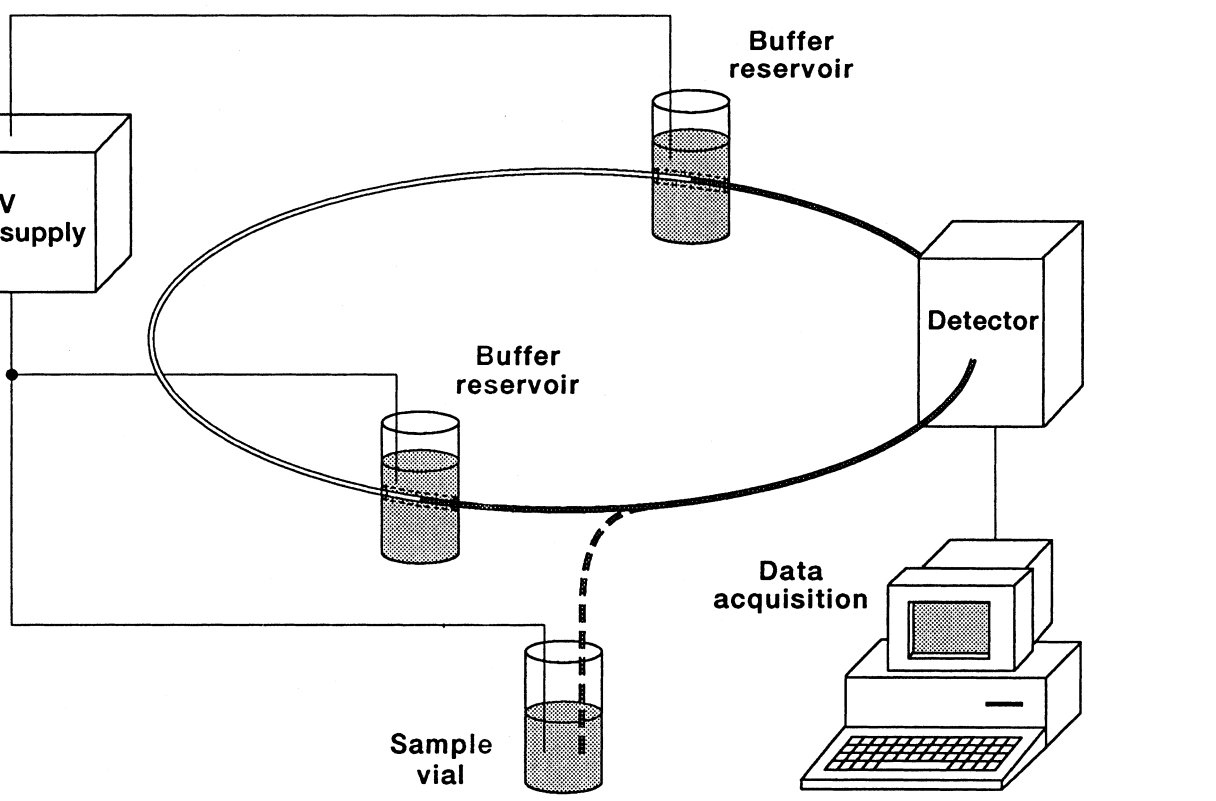

Fig. 6. Schematic representation of the electrophoreton. Reproduced with permission from ref. [52].

components and was shown to offer much higher plate efficiencies than HPLC with packed capillaries. From the potential application of this separation mode to forensic science the high loading capacity as compared to the standard capillary electrophoresis is certainly a considerable advantage. In addition wider range of selectivity will surely help its practical applications in the future.

When compared with other capillary separation modes one has to emphasize the fact that the front of the electroosmotic flow is rectangular as compared to the Poiseuille

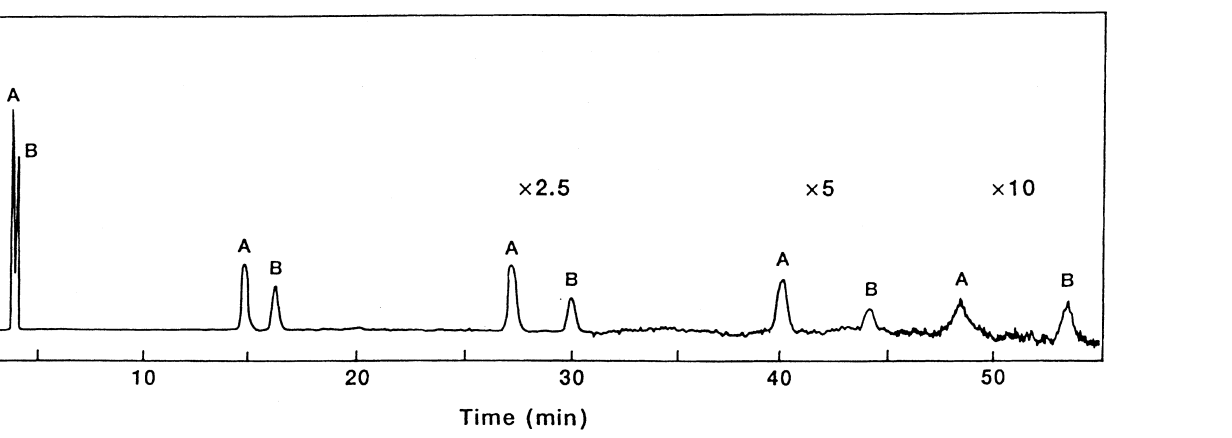

Fig. 7. An electropherogram of two analytes demonstrating better separations as they are repeatedly circulated in the loop. A mixture of $1 \mathrm{mM}$ guanosine (A) and $1 \mathrm{mM}$ benzyl alcohol (B) was injected into the capillary. A $1 \mathrm{mM}$ sample was injected into the capillary. A potential of $10 \mathrm{kV}$ was applied to the system. A buffer solution of $2 \mathrm{mM} \mathrm{NaH} \mathrm{PO}_{4}$ at $\mathrm{pH} 4.5$ was used. Reproduced with permission from Ref. [52]. 
(parabolic) distribution when the solvent is delivered by a micropump. This results in smaller band spreading as demonstrated in the studies published in ref. [56]. In general potential applications in forensic science are likely to be complementary to micellar electrokinetic chromatography.

Knox and Grant [57] have shown that sufficient electroosmotic flow can be obtained with eluent having ionic strength of $0.01 \mathrm{M}$ with columns packed with $1.5 \mu \mathrm{m}$ particles. Most of the published work refers to $50 \mu \mathrm{m}$ i.d. capillaries packed with $3 \mu \mathrm{m}$ diameter sorbent, typically ODS Hypersil. Yamamoto et al. [58] obtained efficiencies of 150200000 plates $\mathrm{m}^{-1}$ and Smith and Evans [59] demonstrated similar efficiency with columns packed with $3 \mu \mathrm{m}$ Spherisorb SCX. This indicates the wide versatility of the technique, as it can exploit not only reversed phase separations, but other (ion-exchange) mechanisms as well.

There are, however, some points that one should be aware of with capillary electrochromatography. First the system should be handled in such a way that it prevents bubble formation within the sorbent bead. This could be prevented either by pressurizing the vials to about $500 \mathrm{psi}$ or by using low conductivity buffers like Tris and MES $[60,61]$. If such precautions are not taken it is difficult to use buffers of higher concentration than $10 \mathrm{mmol}^{-1}$ because degassing at high currents distorts both the detection and the very separation.

The operation mode is not limited to isocratic elution: there are reports on using gradient elution and organic modifiers with the mobile phase [62-64].

One considerable advantage of capillary electrochromatography is the fact that it is routinely carried out with the same instrumentation used for capillary electrophoresis only with minor alterations indeed. Consequently capillary electrochromatographic separations can be hyphenated to the MS detector in a similar way as done with capillary electrophoresis offering thus another MS compatible high resolution separation technique which expands further the scope of multidimensional analysis of complex mixtures.

Fig. 8 shows the scheme of the necessary equipment and the different plates in Fig. 9 depict selected examples of separation.

\subsection{Sample stacking}

Although in capillary electromigration techniques efficiencies reaching 100000 theoretical plates are rather easy to achieve, the major drawback of these techniques is the low concentration sensitivity. Use of capillaries equipped with a bubble cell [65], sample enrichment procedures with extraction or derivatization steps and use of powerful detectors such a laser induced fluorescence detector are some of the approaches to solve this limitation that is of particular importance in forensic analyses where one is frequently faced with samples where the analyte of interest is present in a very small concentration. A simple way of increasing the sample concentration is sample stacking [66-74].

Sample stacking can be achieved generally by two methods: by preparing the sample in the same separation buffer but at lower (about ten times) less ionic strength [75,76] or by including acetonitrile in the sample, called acetonitrile stacking. Under favourable 


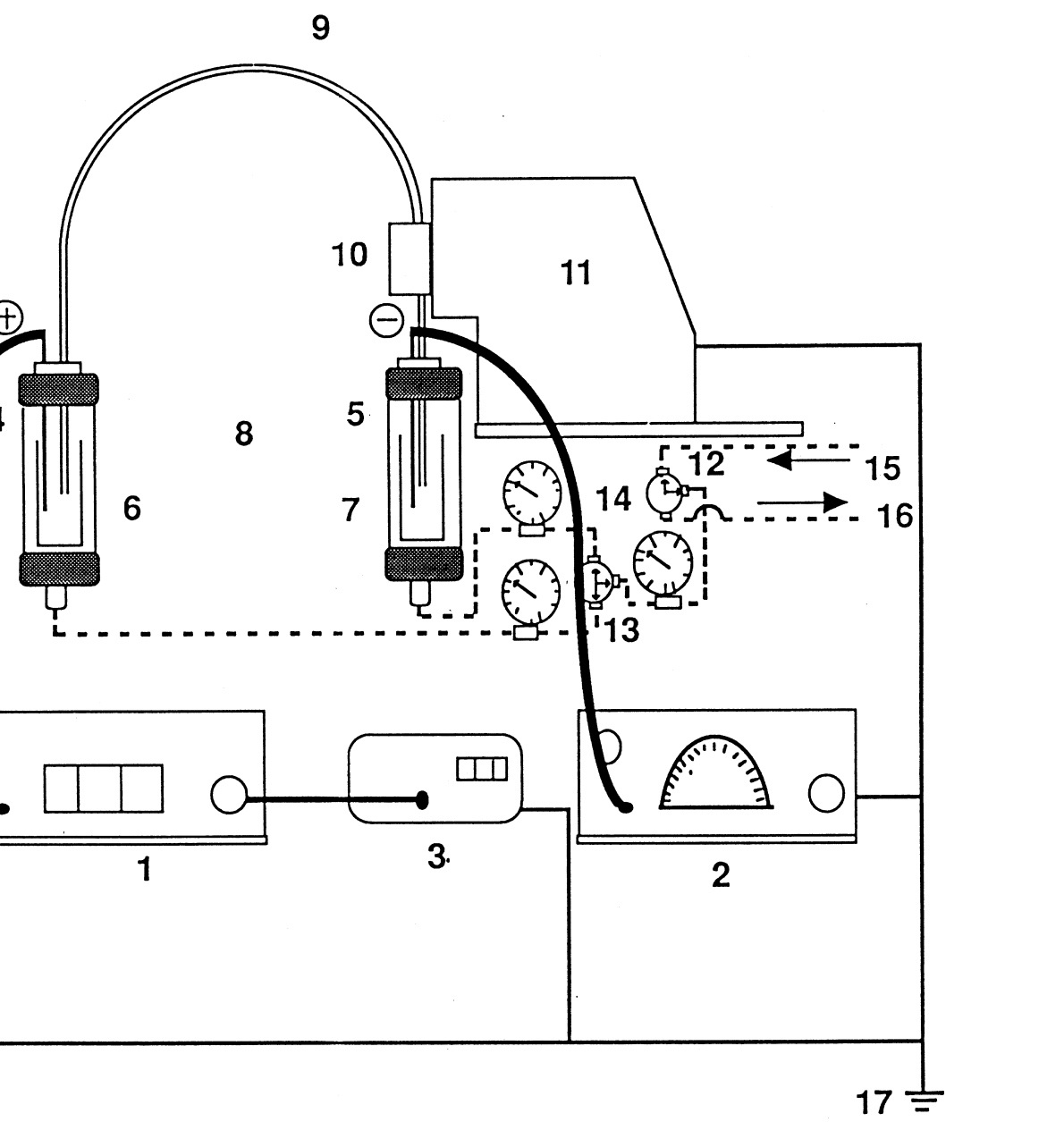

Fig. 8. Schematic drawing of the modular capillary electrochromatograph with a $90 \mathrm{kV}$ dual power supply and pressurizable chambers for the column inlet and outlet. (1) $60 \mathrm{kV}$ power supply, (2) $30 \mathrm{kV}$ power supply, (3) digital electrometer, (4), (5) electrodes, (6)/(7) reservoir for mobile phase or the sample, (8) pressurizable chambers, (9) packed capillary column, (10) cell for on-column detection, (11) detector, (12) 4 port 2 way valve, (13) 4 port 3-way valves, (14) pressure gauges, (15) from nitrogen cylinder, (16) vent, (17) ground. Reproduced with permission from Ref. [60].

circumstances the first way can be replaced by simple dissolving the sample in water. The two mentioned approaches are different while the approach using diluted buffer for sample application deteriorates with increasing ionic strength in the sample, acetonitrile stacking is, on the contrary, improved by an increased sample ionic strength. Acetonitrile stacking is used for samples with high salt or protein concentrations (Fig. 10).

Simple transfer of methods exploiting the ionic strength difference for sample enrichment is, however, not applicable to micellar electrokinetic separations as long as the neutral analytes are not affected either by the enhanced field strength or by the on 

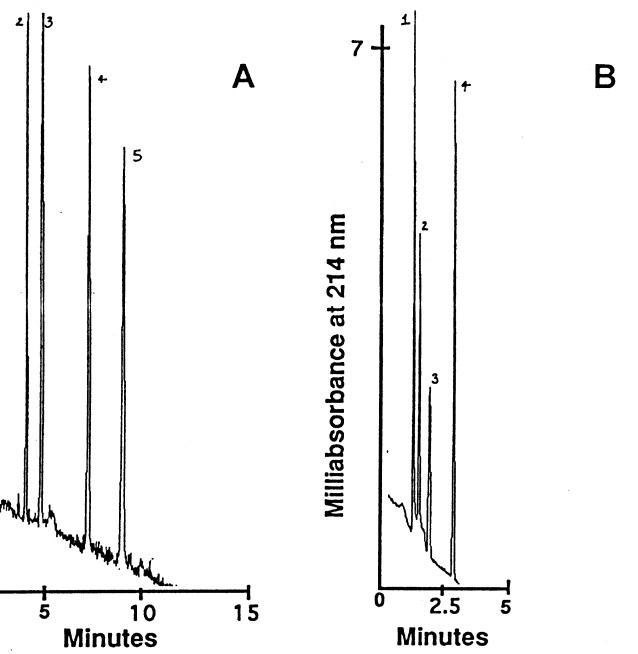

B

C
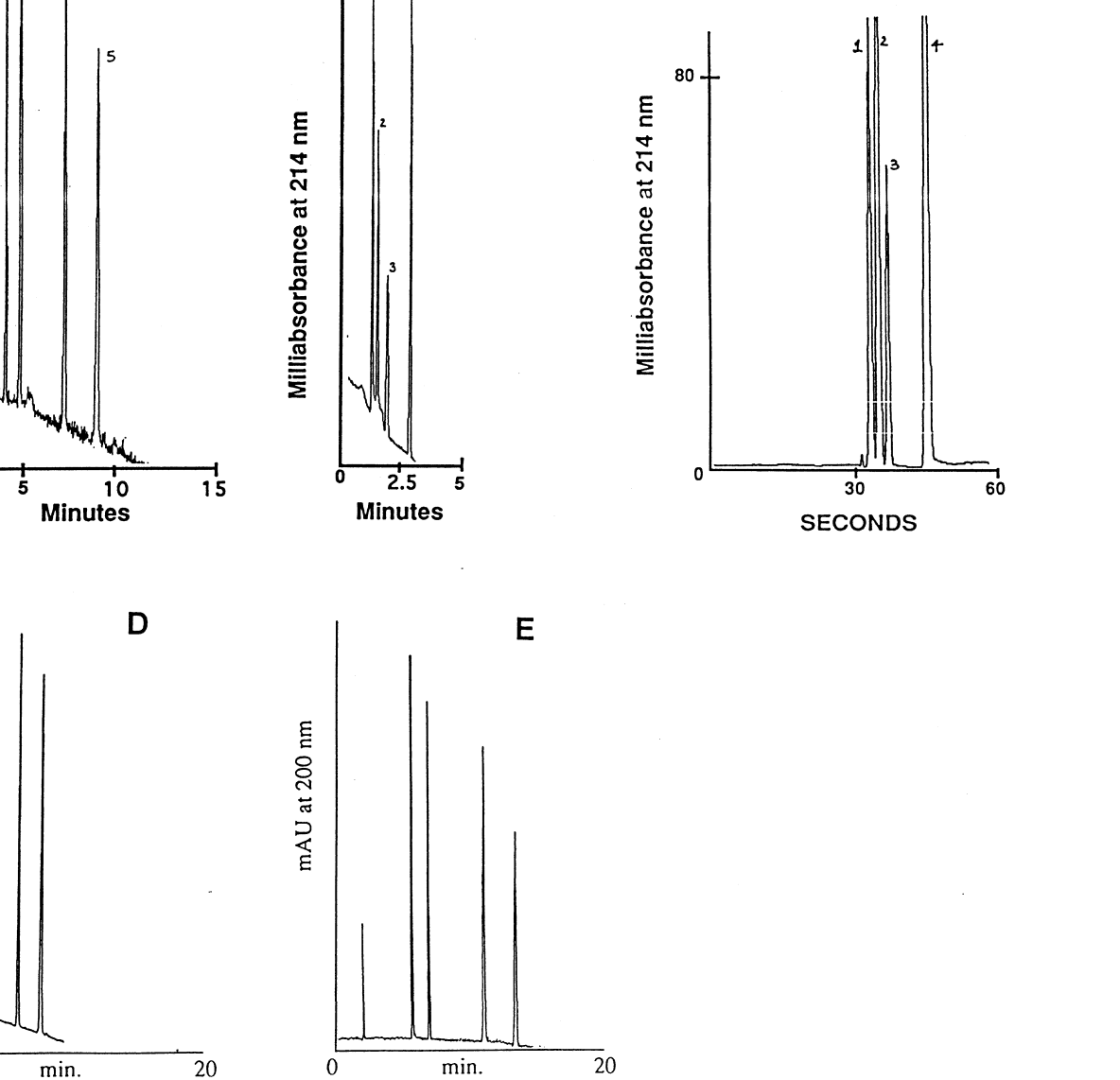

Fig. 9. A-E: Chromatogram of (A) polyaromatic hydrocarbons (B) aromatic acids. (A) Raw fused silica capillary column, $75 \mu \mathrm{m} \times 30 / 39 \mathrm{~cm}$; packed with $3.5 \mu \mathrm{m}$ Zorbax ODS having a mean pore diameter of $80 \AA$. Eluent, 20\% $(v / v) 4 \mathrm{mM}$ borate, $\mathrm{pH} 8.0$ in ACN; applied voltage $30 \mathrm{kV}$. Sample, (1) acrylamide, (2) naphthalene, (3) fluoranthene, (4) biphenyl, (5) $m$-terphenyl; injected for $2 \mathrm{~s}$ at $5 \mathrm{kV}$. (B) Raw fused silica capillary column, $75 \mu \mathrm{m} \times 27 / 36 \mathrm{~cm}$; packed with $6 \mu \mathrm{m}$ Zorbax ODS having mean pore diameter of $80 \AA$. Eluent, $20 \%(v / v) 4 \mathrm{mM}$ borate, $\mathrm{pH} 8.5$ in ACN; applied voltage $30 \mathrm{kV}$. Sample, (1) p-toluic acid, (2) cinnamic acid, (3) p-terbutyl benzoic acid, (4) $o$-dichlorobenzene; injected for $2 \mathrm{~s}$ at $5 \mathrm{kV}$. C: Chromatogram illustrating the rapid separation of small aromatic compounds at $60 \mathrm{kV}$ voltage. Raw fused silica capillary column, $50 \mu \mathrm{m} \times 23 / 32 \mathrm{~cm}$ packed with $6 \mu \mathrm{m}$ Zorbax ODS having a mean pore diameter of $300 \AA$. Eluent, $20 \%(v / v) 10 \mathrm{mM}$ borate, $\mathrm{pH} 8.0$ in ACN. Sample, consisting of acrylamide, (1) benzylalcohol, (2) benzaldehyde, (3) $o$-dichlorobenzene (4); injected for $2 \mathrm{~s}$ at $2 \mathrm{kV}$. (D),(E): Effect of column length in CEC as illustrated by the separation of polyaromatic hydrocarbons on (D) a $40 \mathrm{~cm}$ and (E) a $50 \mathrm{~cm}$ long, $50 \mu \mathrm{m}$ i.d. capillary packed with $3.5 \mu \mathrm{m}$ Zorbax ODS having a mean pore diameter of $80 \AA$ A. Eluent, $20 \%(v / v) 10 \mathrm{mM}$ borate, $\mathrm{pH} 8.0$ in $\mathrm{ACN}$. The applied voltage was $30 \mathrm{kV}$ and $50 \mathrm{kV}$ respectively. Sample, (1) acrylamide, (2) naphthalene, (3) fluoranthene, (4) biphenyl, (5) $m$-terphenyl (in the sense of increasing migration time); injected for $2 \mathrm{~s}$ at $5 \mathrm{kV}$. Reproduced with permission from Ref. [60]. 


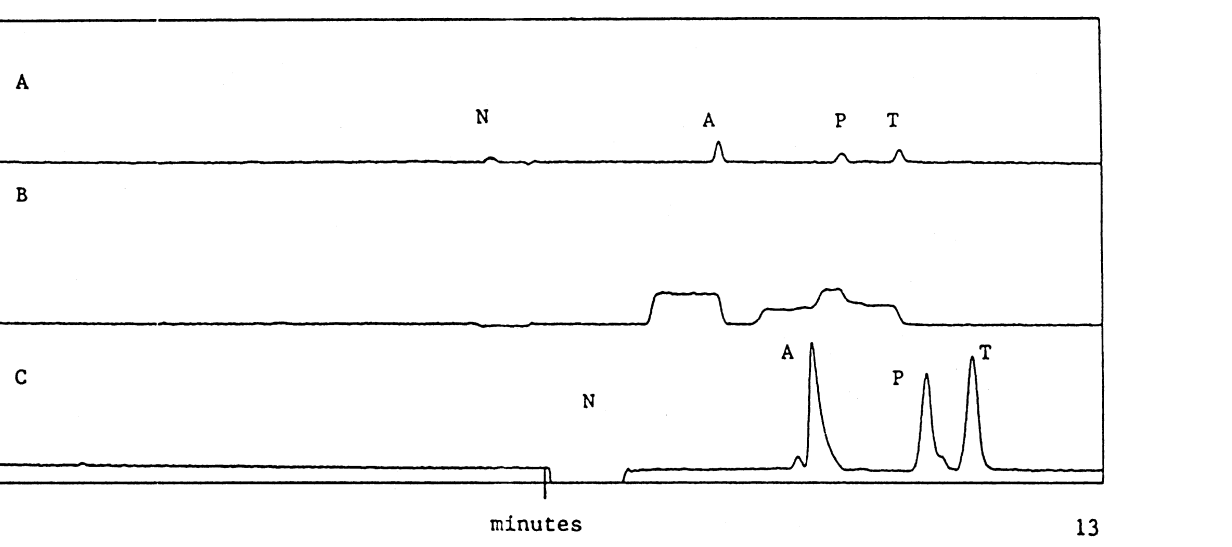

Fig. 10. Comparison of non-stacking to stacking; Sample, a mixture of acetaminophen (A), iopamidol (P) and iothalamic acid $(\mathrm{T})$ dissolved in the electrophoresis buffer $(300 \mathrm{mM})$ and injected at: A- $0.5 \%$ and $\mathrm{B}-8 \%$ loading, and C-the sample dissolved in $1 \%$ saline containing $66 \%$ acetonitrile at $8 \%$ loading. $\mathrm{N}=$ neutral compounds. Reproduced with permission from Ref. [77].

line combination of the isotachophoretic principle with the very capillary electromigration separation. For the purpose of micellar electrokinetic chromatography Liu et al. [74] used a concentration slightly greater than the critical micelle concentration in the sample matrix and calculated the maximum sensitivity enhancement by a factor of 75 based on the peak area counts with normal stacking mode. More recently Quirino and Terabe [78] reported that considerable enhancement of sample concentration can be achieved by enhancing the field in the sample zone by preparing the neutral analytes in water which leads to sample stacking by on-column micellization. These authors have used two anionic high molecular mass surfactants (butyl acrylate-butyl methacrylate copolymer and sodium 10-undecylenate oligomer) and an anionic low-molecular mass surfactant (SDS). It was demonstrated that the stacking efficiency and recovery were independent on analyte retention factors and were slightly dependent on the nature of the pseudostationary phases. Time course of the events is illustrated in Fig. 11.

\subsection{Miniaturized capillary biochemical assays}

Following the attempts to miniaturize biochemical assays a number of various microanalytical techniques have recently appeared: electrophoretically mediated microanalysis (EMMA) that offers the possibility of enzyme assays in the capillary has been recently reported. The method itself is based on the differences in mobility of enzymes, substrates and products [79]. Also the practice of electrophoretic mixing has been introduced to help materialize enzyme assays in a capillary. Yet another approach refers to capillary electrophoresis and on-line post-column microreaction for monitoring enzyme activity [80]. This is visualized in immobilizing a probe on the inner wall of a capillary enzyme reactor $[81,82]$. Unrelated directly to capillary electrophoresis but still using the capillary format are the enzyme immunoassays following the set-up of flow-injection analysis [83]. 
A

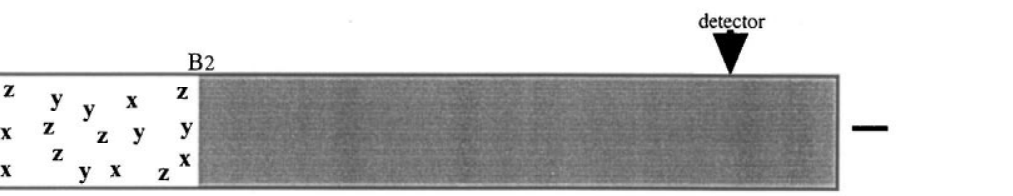

B

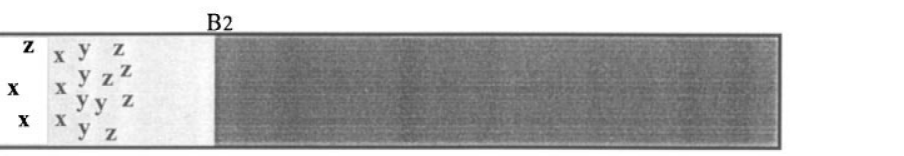

C

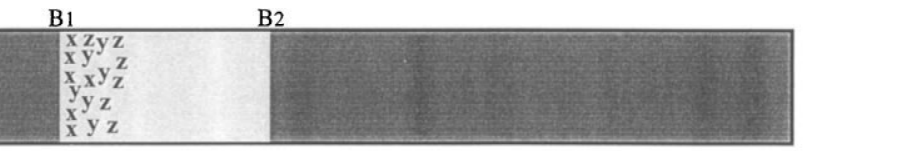

D

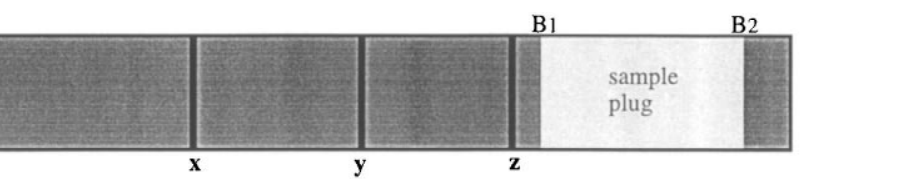

Fig. 11. Evolution of neutral analytes in $\mathrm{S}$ and BGS during stacking. A, starting situation: B, high velocity micelles in $S$ carry the neutral analytes to the opposite concentration boundary $B_{1}$ in the order of decreasing retention factor $k(\mathrm{x})>k(\mathrm{y})>k(\mathrm{z})$; C, neutral analytes stack in $\mathrm{B}_{1}$ into thin concentrated zones; $\mathrm{D}$, analyte zones separate by virtue of MEKC. Reproduced with permission from Ref. [78].

On-line sample preconcentration in capillary electrophoresis is another emerging development in microanalysis (see also the section on sample stacking) [84]. For instance multiple capillary bundles coupled to a single capillary can serve as an analyte concentrator [85]. Other alternatives used for this purpose are capillaries packed with a reversed-phase sorbent or the use of impregnated membranes [86,87].

Yet another operation which can be done on-line is dialysis. This can be materialized in a sandwich-like compartment [88].

To exploit fully the specific binding (affinity) principle in capillary electrophoresis it is necessary to use partially or completely filled capillaries, the preparation of which need not be quite easy. Solid supports in capillaries frequently require frits to maintain the particles in the column which is another complication [89].

Quite recently Raskhovetsky et al. [90] exploited the unique property of magnetic beads. These sorbents can be surface modified for a wide variety of applications including immunoassays, cell sorting, immobilized enzyme reactions and a variety of bioaffinity methods [91,92]. The experimental set up is based on a commercial 
instrument into which magnetic beads are injected at low pressure and kept in place by a magnet during the analysis. Subsequently these beads can be removed in the wash phase. Two operational modes, namely sequential injection and sequential injection followed by isotachophoretic focusing were shown to be applicable for enzymatic assays, inhibition analysis and immunotrapping with antigen determination.

Regarding methods for monitoring enzymatic activity recently a procedure for monitoring phosphatidylinositol specific phospholipase activity has been reported [93]. This enzyme converts phosphatidylinositol to diacylglycerol and inositol 1,3-cyclic phosphate. The method allows monitoring both the substrate (its breakdown) and formation of the products. MALDI measurements offered the possibility to determine the molecular masses of the substrate and the products.

Individual stages of the analysis in antigen immunotrapping and ITP focusing and the result of the analysis are shown in Figs. 12 and 13.

Another possibility offered by the miniaturized capillary techniques is the study of interactions (for reviews see $[94,95]$ ).

The basic idea here is to exploit different migrations of free as compared to complexed analyte to quantitate and characterize binding interactions [96,97]. This approach obviously requires that the migration velocity of the complexed and uncomplexed analyte are different. On the other hand with the high dependence of analyte mobility on the charge/mass ratio (in the simplest case) $[96,98,99]$ this can be expected to occur at least in situations where the capillary separation is predominantly following the Offord's rule. In practice this approach is frequently used for revealing proteinprotein interactions (for a recent report see ref. [100]).

\subsection{The "chip" technology}

A number of devices have been recently described for miniaturized separations [101-106]. Their common feature is the use of a glass or more recently quartz plate with an appropriate set of rims which replace the separation capillary and serve the purpose of delivering the sample and wash solutions into the system. The disadvantage at the moment is that such devices are only laboratory constructed and are not commercially available. Though the principle is rather simple, the practice of manufacturing such manifolds is anything but easy. The layout of such a chip is demonstrated in Fig. 14. Even though the separation length in such devices is only of about $50 \mathrm{~mm}$ the efficiency obtained is comparable to the efficiency of conventional capillary electrophoresis (160 000 theoretical plates can be easily achieved). The separations are run at about 5 $\mathrm{kV}$ which ensures adequate voltage gradient over the separation capillary. Regarding the background electrolytes used conventional buffers of the concentration of about 60 mmol $\mathrm{l}^{-1}$ seem to be adequate for the analysis. Another advantage of this arrangement is that sample transport, injection and all sample handling steps (including possible on-line derivatization) can be easily controlled by switching the voltage applied: If the sample is placed in the reservoir 1 and voltage is applied between positions 1 and 3 for a short period of time, the sample fills a small segment of the separation capillary. Next the voltage is switched of and applied again between positions 2 and 6 which ensures a very precise sample loading. The analysis time with these devices is cut down to amazing 
Step 1. Sample Injection

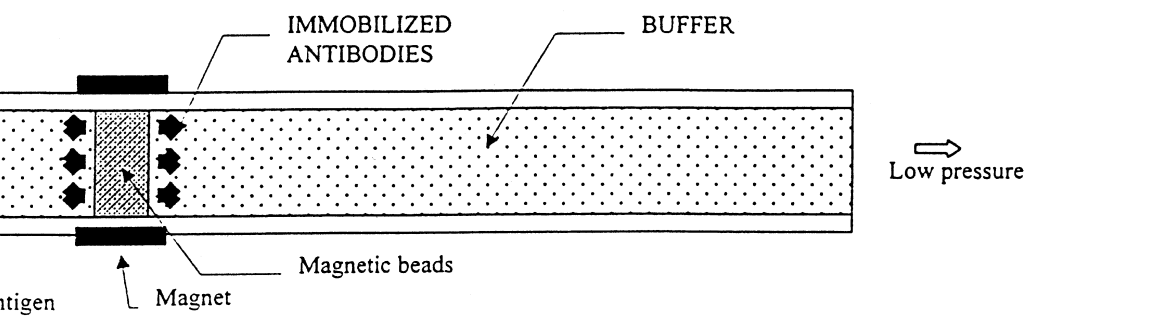

Step 2. Rinsing.

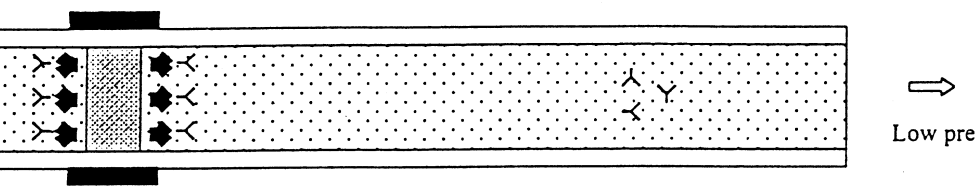

Step 3. Elution,

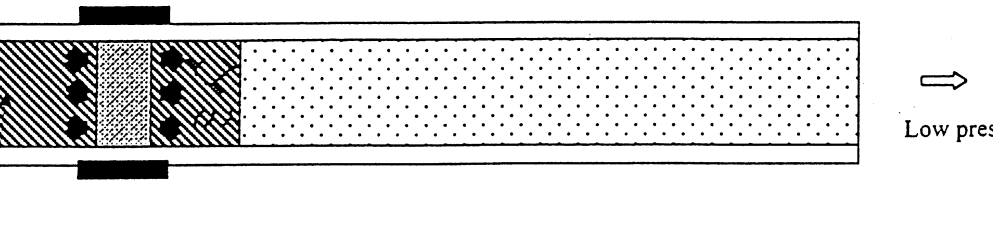

Boundary

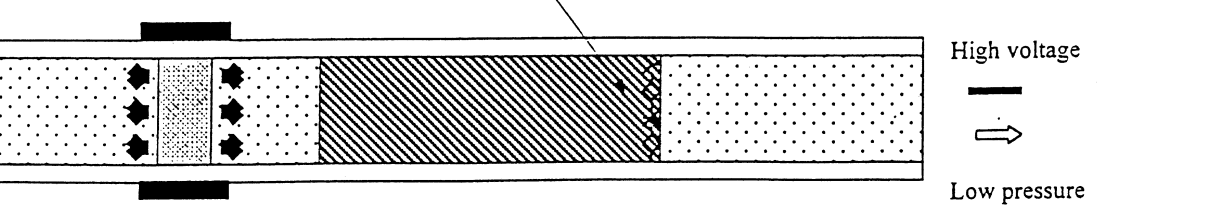

Fig. 12. Schematic of magnetic bead phased separation. Two solid lines surrounding the capillary represent a magnet that keeps the magnetic beads in a particular section of the capillary. From Ref. [90] with permission.

tenth of seconds as compared to half an hour with the standard device. Successful attempts to modify the surface of the capillary by e.g. polyacrylamide were also reported [106].

Some idea about the efficiency of the chip separations with the conventional capillary electrophoresis is visualized in Table 1 and in ref. [108].

Naturally this approach is at the stage of equipment development and has not been 


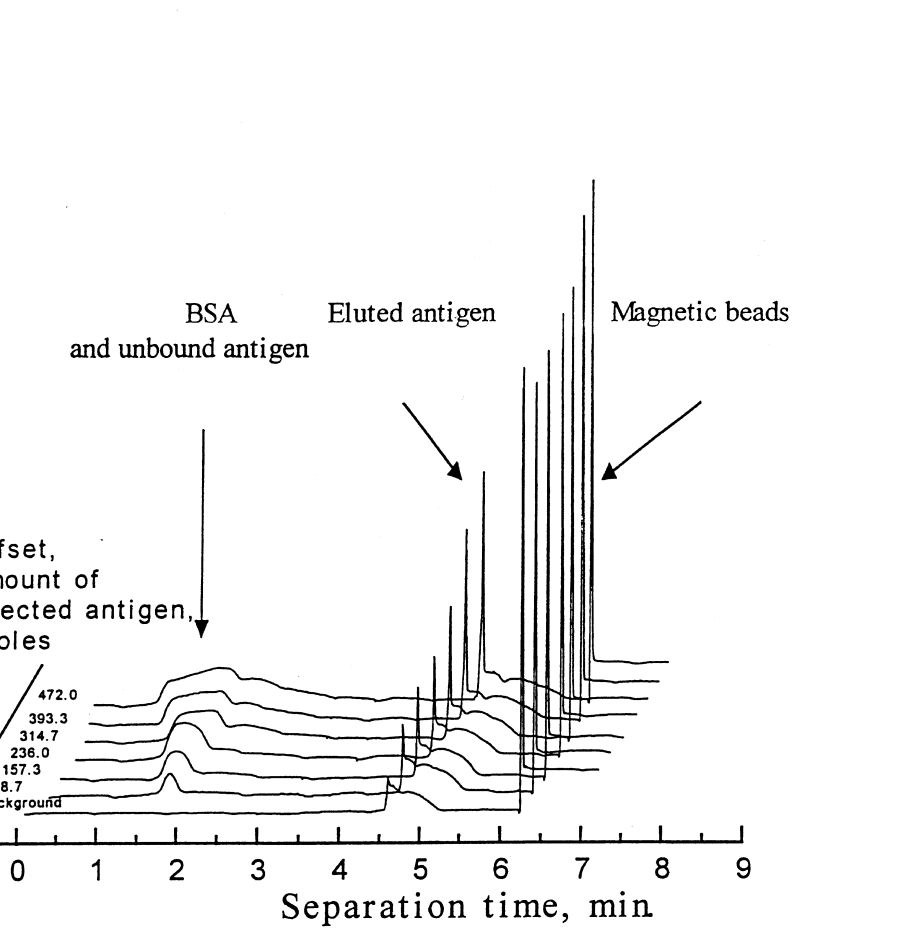

Fig. 13. Separation of $0-472$ fmols of an antigen; separation conditions as in Fig. 12. With permission from Ref. [90].

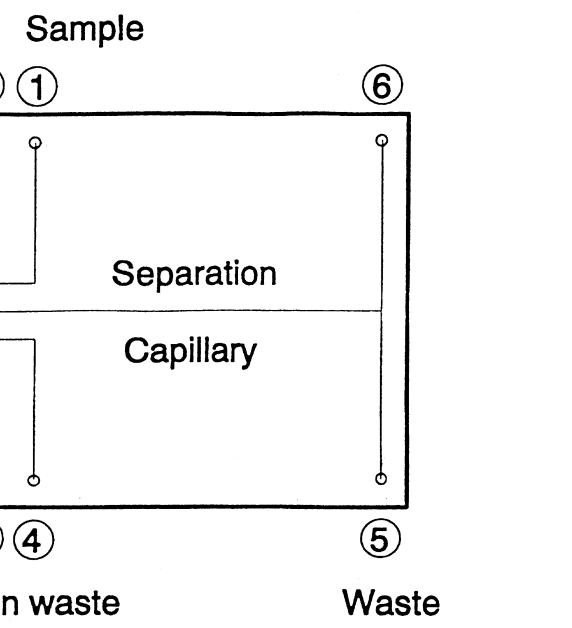

Fig. 14. Layout of a glass chip for capillary electrophoresis. With permission from Ref. [107]. 
Table 1

Comparison of separation of amino acids using HPLC (4 mm column), conventional capillary electrophoresis (CE) on $75 \mu \mathrm{m}$ capillary, and chip technology $(50 \times 12 \mu \mathrm{m}$ channel $)$

\begin{tabular}{llll}
\hline & HPLC & CE & Chip \\
\hline Analysis time & $30 \mathrm{~min}$ & $20 \mathrm{~min}$ & $20 \mathrm{~s}$ \\
Cycle time & $45 \mathrm{~min}$ & $25 \mathrm{~min}$ & $30 \mathrm{~s}$ \\
Flow-rate & $1.5 \mathrm{ml} \mathrm{min}^{-1}$ & $350 \mathrm{nl} \mathrm{min}^{-1}$ & $200 \mathrm{nl} \mathrm{min}^{-1}$ \\
$\begin{array}{l}\text { Mobile phase } \\
\text { consumption }\end{array}$ & $68 \mathrm{ml}$ & $9 \mu \mathrm{l}$ & $100 \mathrm{nl}$ \\
\hline
\end{tabular}

According to Effenhauser and Manz [107].

exploited for forensic applications so far. However, the potential equals that of standard capillary electrophoresis and it is likely that chip separations will became popular as soon as the adequate equipment is commercially available.

\subsection{CE-MS hyphenation}

The first papers involving coupling of capillary electrophoresis to a MS instrument were published in the late eighties and since then numerous papers have been published on this subject concerning mainly quadrupole, ion trap, cyclotron resonance and electrospray or continuous flow fast atom bombardment interfaces. Low sensitivity, increased background noise and less applicability to high molecular mass solutes experienced when using continuous flow fast bombardment spectrometry permitted electrospray techniques to dominate the field [109]. As developed over the years this technique is currently applicable nearly to the same categories of compounds as capillary electrophoresis: ionic, polar, no matter whether high or low molecular mass solutes can be analyzed. The technique, however, is not applicable to neutrals (which in capillary electrophoresis can be separated by micellar electrokinetic chromatography) [110-114].

The widespread use of electrospray is due to its multiple advantages: high ionization efficiency, multiple charging of molecules which yields ions of mass-to-charge ratios compatible with the operating mass range of most analyzers, soft nature of the ionization technique with no or little fragmentation and ultimately the fact that it exploits an atmospheric ionization source are the fundamental plausible characteristics.

Several reports on interfacing capillary electrophoresis to time-of-flight spectrometry were reported during the last three years [115-121]. These studies were conducted using an electrospray ionization source. The desirable attributes of time-of-flight mass spectrometry such as speed, unlimited mass range, high transmission efficiency, high duty cycle and sensitivity are well compatible with the properties of capillary electrophoresis.

From the practical point of view the crucial point of any hyphenation is the interface. Recently a simple and apparently very useful construction has been published by Lazar et al. [122].

The assembly is schematically drawn in Fig. 15. This construction is based on an earlier experience of the authors [122,123]. In addition to liquid sheath and make-up gas capabilities it incorporates the possibility of a nebulizing gas as well. 


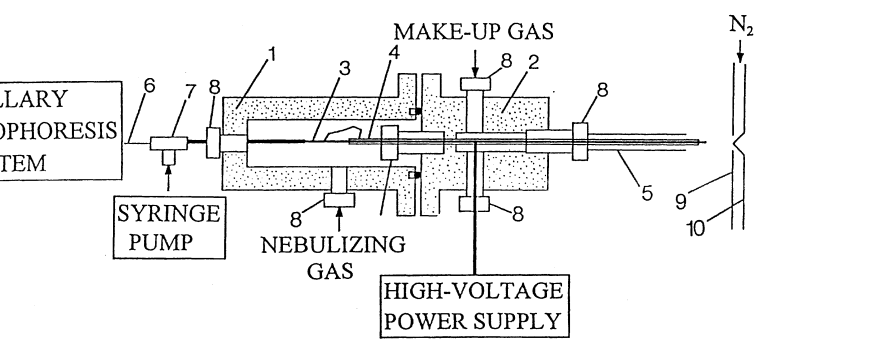

Fig. 15. Schematic diagram of the electrospray source. (1) Electrospray chamber 1 (Tefzel); (2) Electrospray chamber 2 (Tefzel); (3) Electrospray needle; (4) Nebulizing tubing (stainless steel); (5) Make-up gas tubing (glass); (6) CE capillary; (7) Teflon T-union; (8) Nuts, tubing connector (Delrin); (9) Interface plate; (10) Nozzle. With permission from Ref. [122].

The interface consists of two main chambers made out of Tefzel $(1,2)$ screwed together. The electrical contact for electrospray operation which, as usual, represents also the electrical contact for the capillary electrophoresis device at the detection end is realized through a liquid sheath supplied through the electrospray needle (3). The gauge of the ESI needle was chosen such that its i.d. matched as close as possible the i.d. of the fused silica capillary used in the electrophoresis section. The electrospray voltage is applied through a spring loaded contact to the stainless steel tubing which supplies the nebulizing gas (4). Electrical connection to the electrospray needle is provided through a removable contact wire between tubing 3 and 4 in the electrospray chamber 1 . The constant liquid flow for the sheath electrode is supplied by a syringe pump through a small T-piece (7).The fused silica capillary from the separation section is joined to the same T-piece (7) and protruded slightly from the ESI needle.

The construction allows for applying additional make-up gas if necessary through electrospray chamber 2. Chambers 1 and 2 are insulated from each other so that mixing of the nebulizing and make-up gas cannot occur. The reason for using of the make-up gas is to suppress electrical discharge.

An electrospray focusing lens (9) is placed in front of the mass spectrometer sampling nozzle (10). The curtain gas (counter current flow of heated nitrogen) is supplied between the nozzle and the electrospray focusing lens. The curtain gas helps with the desolvation of the electrosprayed droplets, minimizes ion-solvent cluster formation and prevents the nozzle orifice from contamination by microparticulates.

Just to show the practical applicability of capillary electrophoresis let us mention the paper of Zhao et al. [124] who analyzed tetramine, an autonomic ganglionic blocking agent found in several marine gastropod species responsible for a number of human intoxications. Other typical examples regarding peptide analysis are shown in Figs. 16 and 17. In the latter case MALDI-TOF-MS was used for identifying the prairie rattlesnake myotoxins.

\subsection{Other types of hyphenation}

It appears that at least two other types of hyphenation may become useful in the future. One is interfacing capillary electrophoresis with low temperature (4.2 K) 

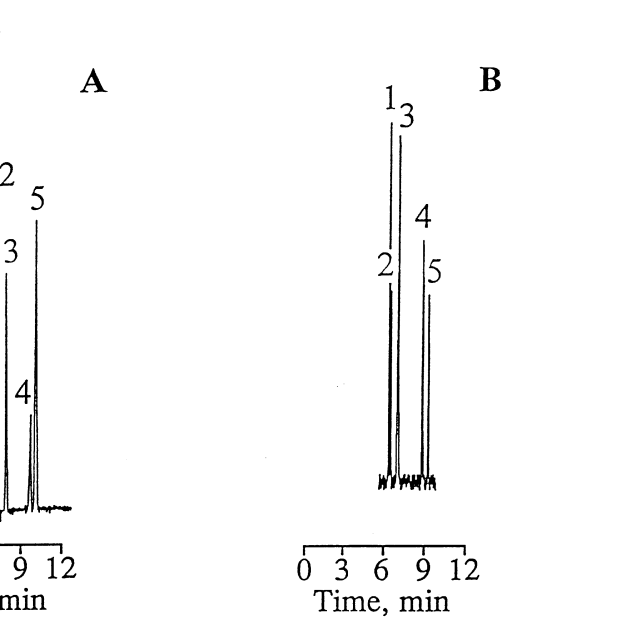

Fig. 16. CE-UV and CE-TOFMS separation of peptides. (A) CE-UV: $90 \mathrm{~cm} \times 50 \mu \mathrm{m}$ i.d. amine-coated fused silica, $0.3 \% \mathrm{CH}_{3} \mathrm{COOH} / \mathrm{H}_{2} \mathrm{O},-25 \mathrm{kV},-278 \mathrm{~V} \mathrm{~cm}{ }^{-1}$. $-2.1 \mu \mathrm{A}, 10 \mathrm{mbar}, 30 \mathrm{mbar} \times 0.3$ min injection ( 1-1.2 pmol from a 110-130 $\mu \mathrm{M}$ solution), $210 \mathrm{~nm}$ at $75 \mathrm{~cm}$. (B) CE-TOF: $75 \mathrm{~cm} \times 50 \mu \mathrm{m}$ i.d. amine-coated fused silica, $0.3 \% \mathrm{CH}_{3} \mathrm{COOH} / \mathrm{H}_{2} \mathrm{O},-25 \mathrm{kV},-369 \mathrm{~V} \mathrm{~cm}^{-1} .-2.8 \mu \mathrm{A}, 10 \mathrm{mbar}, 30 \mathrm{mbar} \times 0.15$ min injection ( $\sim 60-700 \mathrm{pmol}$ from a $110-130 \mu \mathrm{M}$ solution). Liquid sheat: $0.5 \mu 1 \mathrm{~min}^{-1}, \mathrm{CH}_{3} \mathrm{OH} / \mathrm{H}_{2} \mathrm{O} /$ $\mathrm{CH}_{3} \mathrm{COOH}(80: 20: 0.1 \mathrm{v} / \mathrm{v})$, ESI $2700 \mathrm{~V}, 90^{\circ} \mathrm{C}$. MS data acquisition: $5000 \mathrm{~Hz}, 5000$ spectra averaged, 1 data point $\mathrm{s}^{-1}$. Peak identification: (1) Phe-Gly-Gly-Phe, (2) Ala-Gly-Ser-Glu, (3) Val-Pro-Leu, (4) Arg-GlyAsp, (5) Gly-Gly-tyr-Arg. With permission from Ref. [122].

fluorescence line narrowing spectroscopy for resolving and spectral characterization of closely related analytes. In regard to selectivity, it has been shown that various stereoisomers and different conformations of polyaromatic hydrocarbon-DNA adducts can be resolved by this technique $[125,126]$. Concerning versatility, fluorescence line narrowing spectroscopy has been applied to polyaromatic hydrocarbons $[127,128]$, and nucleoside/nucleotide DNA adducts in vivo and in vitro [129-132]. A variety of other fluorescent analytes including thiazole dyes [133], squaraine dyes [134], chlorophylls [135,136], heme proteins [137] and cytochromes [138] have also been characterized by this spectroscopic method, though the combination with capillary electrophoresis has not been explored in the past. Construction of the appropriate interface as reported Zamzow et al. [139] allowed on-line measurements of fluorescence spectra (Fig. 18). The system consist of a modular CE apparatus coupled to a capillary cryostat and high resolution spectrometer system. The capillary cryostat consists of a double walled quartz cell inlet an return lines for introducing liquid nitrogen or liquid helium. The outer portion of the capillary cryostat is evacuated. The capillary positioned in the central region of the capillary cryostat can be cooled to 77 or $4.2 \mathrm{~K}$ after the capillary separation is complete, by a continuous flow of liquid nitrogen or helium through the cryostat. Liquid helium is necessary for laser-excited experiments. Non-line narrowed fluorescence spectra acquired at $77 \mathrm{~K}$ provide information including the wavelength of the $0-0$ band and the vibronic band structure of capillary electrophoresis separated analytes. An example showing the separation of two benzopyrenes and the respective spectra are shown in Fig. 19. 


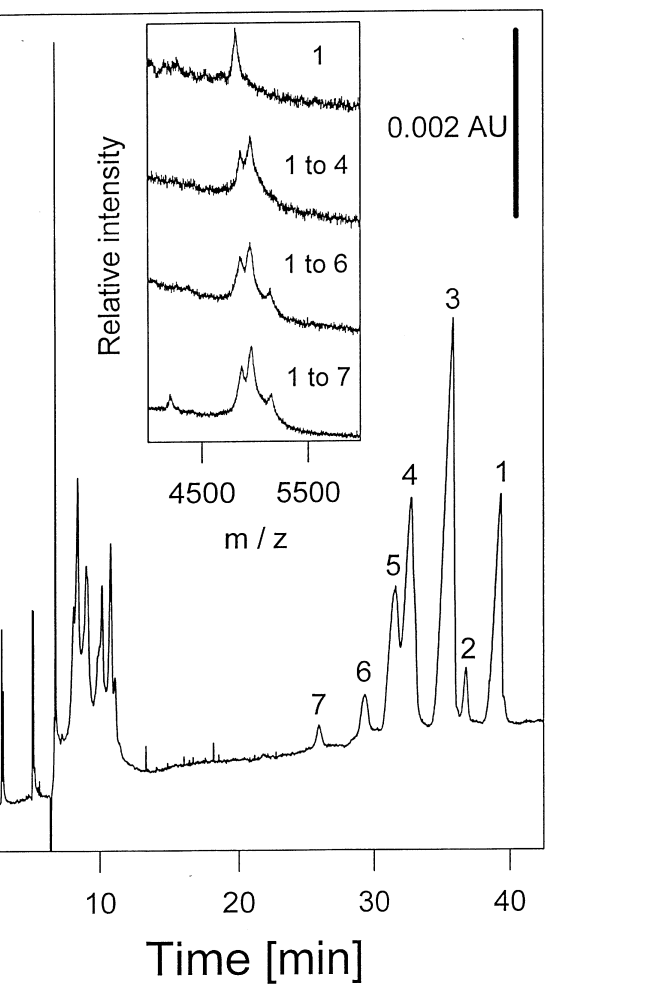

Fig. 17. CE separation of Crotalus viridis helleri venom. Conditions: $67 \mathrm{~cm} \times 50 \mu \mathrm{m}$ I.D., $0.1 \mathrm{M}$ PEI coated capillary; $0.1 \mathrm{M}$ acetate buffer $\mathrm{pH} 4.0$; voltage, $20 \mathrm{kV}$; temperature, $25^{\circ} \mathrm{C}$. Sample concentration and injection, $5 \mathrm{mg} \mathrm{ml}^{-1}, 5 \mathrm{~s}$. Inset: MALDI-TOF-MS of various myotoxin fractions collected from the CE separations of the C. v. helleri. With permission from Ref. [208].

Another way of exploiting combination of fluorescence spectroscopy with capillary electrophoretic separations is to use synchronous fluorescence spectroscopy or evaluation of the separated fractions (on-line measurement has not been described yet). The separation and partial identification of fluorescent post-translational modification products in collagen may serve as a good examples (Fig. 20).

\subsection{New detection modes}

A proton induced X-ray emission (PIXE) detector has been recently used to detect inorganic species, no matter whether bound in e.g. a protein or analysed as such. The detected X-rays are generated inside the capillary by an accelerated proton beam The application of this novel detection mode in addition to common UV detectors operated mostly in the negative mode has been demonstrated for different complexes of gadolinium with polyamino polyacetic acids. Also the applicability of this approach has 


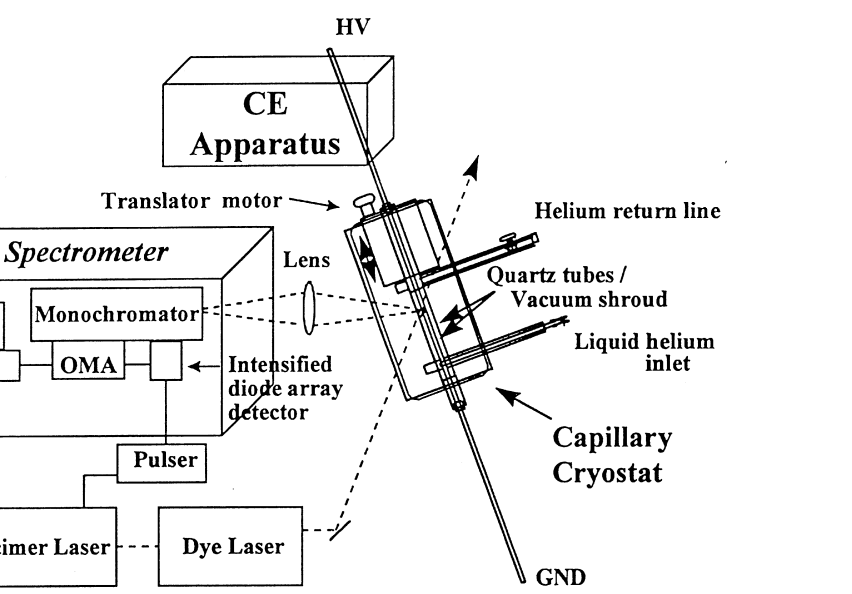

Fig. 18. Schematic diagram of the capillary electrophoresis-fluorescence line narrowing system used for structural characterization of CE-separated analytes. With permission from Ref. [139].

been demonstrated with the six isoforms of metalothioneins isolated form rabbit liver and horse kidney. Copper, zinc and cadmium attached to these isoforms can be detected simultaneously (Fig. 21) [140].

Another application is the identification of fountain pen inks (actually in combination with fluorescence detection of individual peaks as described by Vogt et al. [141].
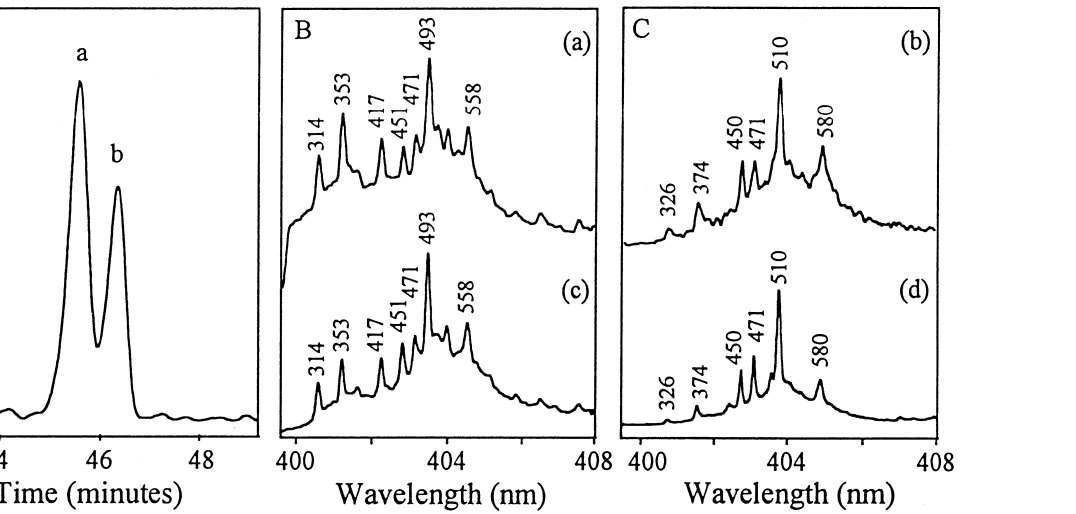

Fig. 19. (A) Room-temperature fluorescence electropherogram for a mixture of (a) $\mathrm{B}[a] \mathrm{P}-\mathrm{d}_{12}$ and (b) $\mathrm{B}[a] \mathrm{P}$ using a CE buffer consisting of $40 \mathrm{mM}$ sodium bis(2-ethylhexyl)sulfosuccinate and $8 \mathrm{mM}$ sodium borate in acetonitrile-water $(30 \% v / v), \mathrm{pH} 9$; capillary $85 \mathrm{~cm} \times 75 \mu \mathrm{m}$ i.d.; $25 \mathrm{kV}(50 \mu \mathrm{A})$. FLN spectra in the CE-buffer matrix at $T=4.2 \mathrm{~K}, \lambda_{\mathrm{ex}}=397 \mathrm{~nm}$, were obtained for the CE-separated analytes (a) and (b). Spectra (c) and (d) are from the library of FLN spectra of PAHs for $\mathrm{B}[a] \mathrm{P}-\mathrm{d}_{12}$ and $\mathrm{B}[a] \mathrm{P}$, respectively. The FLN peaks are labeled with their $S_{1}$ vibrational frequencies, in $\mathrm{cm}^{-1}$. With permission from Ref. [139]. 


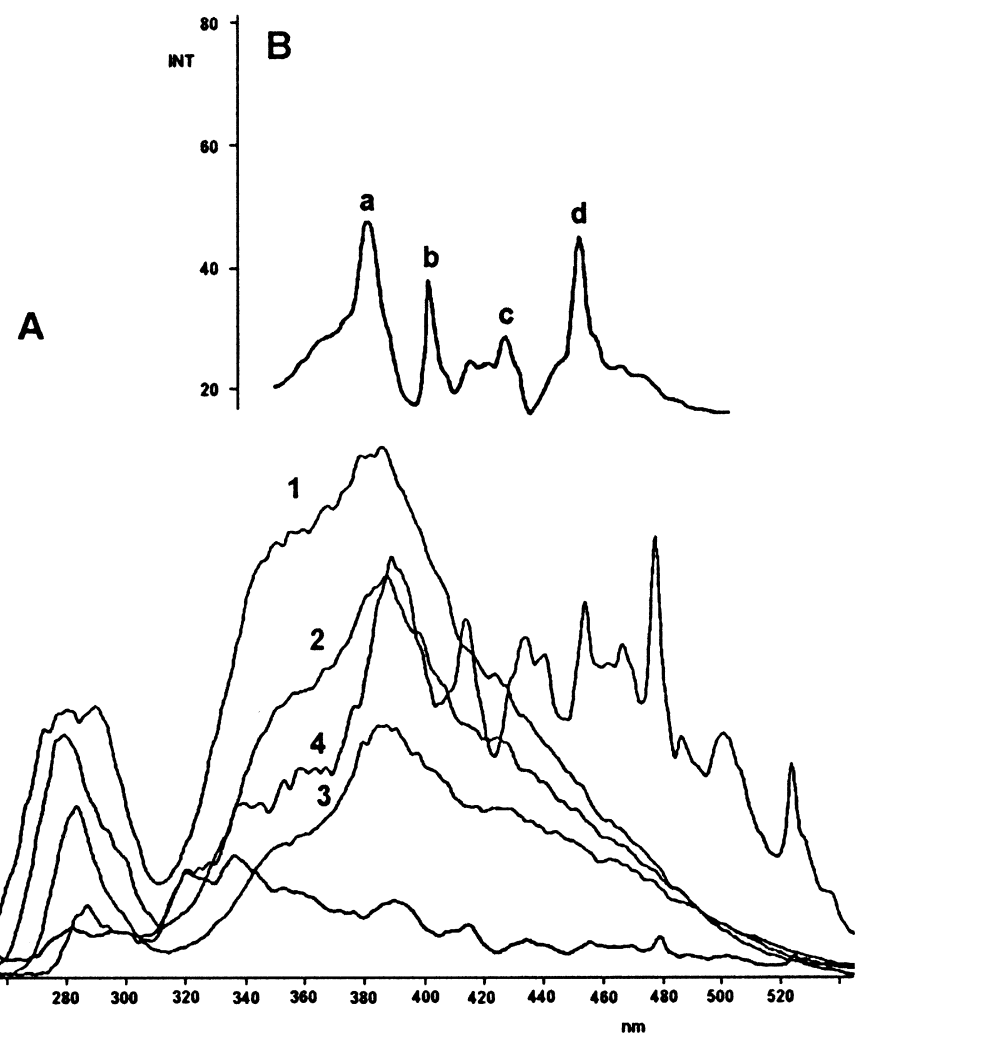

Fig. 20. Synchronous fluorescence spectra of commercial type I collagen preparation at different $\Delta \lambda(1-40 \mathrm{~nm}$, 2-30 nm, 3-20 nm and 4-10 nm) (A) and comparison with a model mixture of standards (a-pentosidine, b-pyridinoline, c-4,5(E)-epoxy-2(E)-decenal and 4,5(E)-epoxy-2(E)-heptenal adducts, d-malondialdehyde adduct) (B).

\section{Selected applications}

\subsection{Chiral separations}

Chiral separations are attaining more and more attention particularly because of the fact that a number of environmental toxicants possess a chiral center and the different stereoisomers possess different toxicity (about e.g. $25 \%$ of agrochemicals are chiral compounds). In comparison with chiral HPLC separations capillary electrophoresis offers a more straightforward separations which are more easy to interpret as long as the interactions allowing for stereoisomer separations occur directly with a chiral selector added to the background electrolyte. The most common chiral selectors are optically active micelles [142], cyclodextrins [143-146], derivatized cyclodextrins [147,148], ligand exchangers [149], macrocyclic antibiotics [150,151], polymeric stereoselective modifiers [152], glycosaminoglycans [153], and crown ethers [154-159]. In some instances the chiral selector has been bound to the capillary wall or included into a gel 

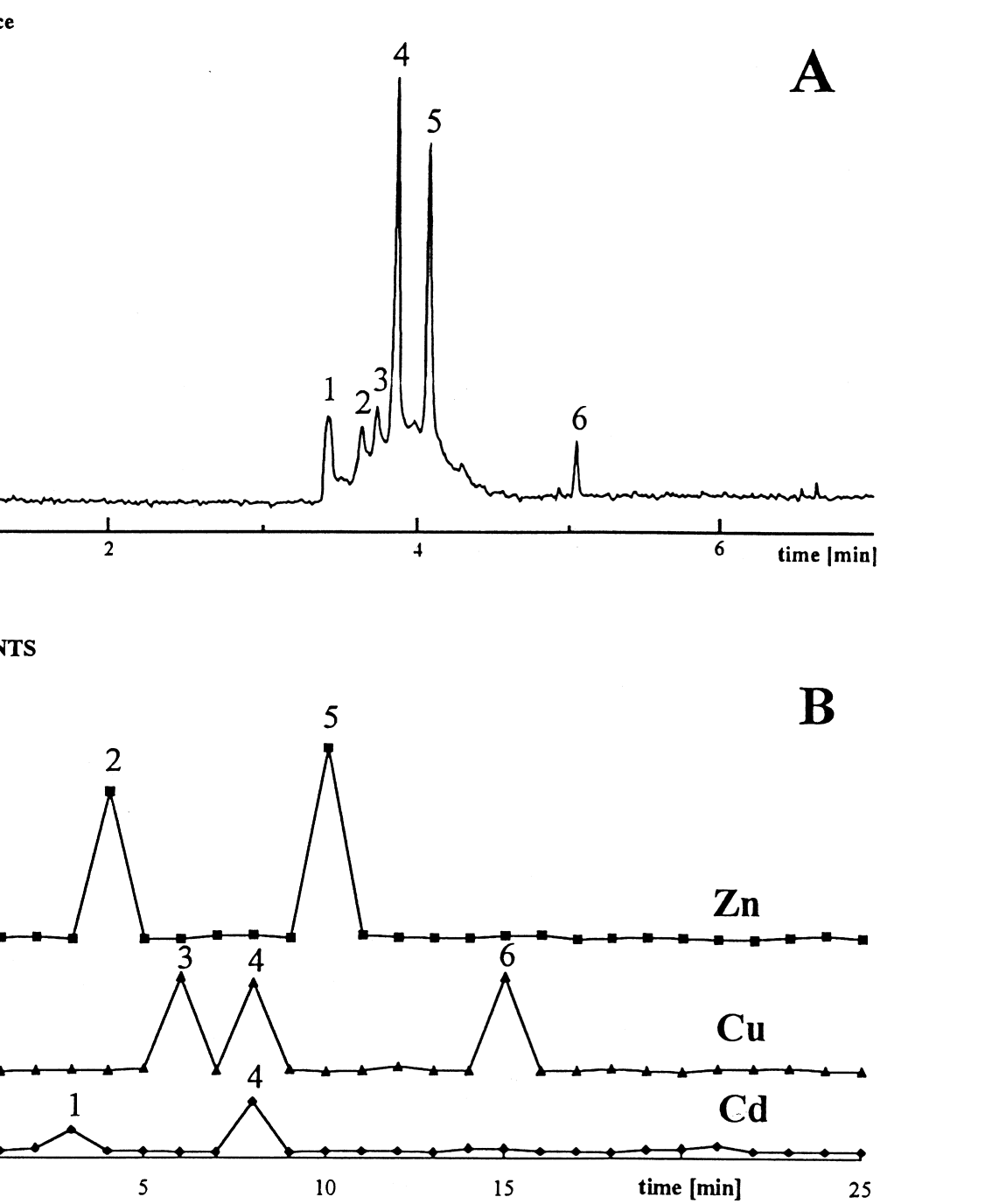

Fig. 21. Separation of rabbit liver metallothionein in A $20 \mathrm{mM}$ phosphate $\mathrm{pH} 6.0,20 \mathrm{kV}$, UV detection at 200 $\mathrm{nm}$ and $\mathrm{B} 20 \mathrm{mM}$ phosphate $\mathrm{pH} 6.0,10.5 \mathrm{kV}$, PIXE detection; metallothionein concentration $0.5 \mathrm{mg} 1^{-1}$. With permission from Ref. [140].

[154,155]; examples of enantiomeric resolution using packed capillaries (capillary electrochromatography) have also been shown [160].

Optically active micelles are of two types; the first category are micelles which are formed from an optically active surfactant like sodium dodecyl-L-valinate. Owing to the fact that such surface active agents have to be synthesized in the laboratory which is not an easy task, complexes of non-chiral surfactants with a hydrophobic chiral selector are preferred; the most common version are, perhaps, complexes of SDS with L-aminoacid 
esters. In some cases two different selectors are used simultaneously in combination or the selectivity can be modified by using the addition of an organic solvent to the background electrolyte. This is particularly true with cyclodextrins, which are effective only when the molecules to be separated possess a favourable structure such that the chiral center which interacts through the three point mechanism with the rim of the cyclodextrin cycle has a favourable distance from the hydrophobic domain of the molecule which penetrates the cyclodextrin cavity.

The above mechanism assumes that the chiral compounds are well soluble in aqueous buffers which need not necessarily be always the case. In such a case organic-aqueous buffers can be the remedy to achieve the separation. If the structure of the stereoisomeric solutes is unfavourable for the separation via inclusion complexes formation with cyclodextrins, successful results can be obtained with chiral crown ethers or a combination thereof. Typically when stereoisomers of primary amines cannot be separated by $\beta$-cyclodextrin alone, addition of non-chiral 18 -crown-6, 1,4,7,10,13,16hexaoxacyclooctadecane, to the background electrolyte offers good separations [161]. Generally saying the application of non-chiral 18-crown-6 in combination with e.g. $\beta$-cyclodextrin can be one of the first choices when attempting to separate stereoisomers of e.g. non-polar primary amines.

Instead of the above combination of non-chiral crown with $\beta$-cyclodextrin, similar results can be obtained with the chiral 18 -crown- 6 tetracarboxylic acid; however, the price of this stereoselective modifier precludes it from wider application.

Up to now, a number of enantiomer separations have been reported using not only natural cyclodextrins, but also derivatized cyclodextrins. In particular, methylated and hydroxypropylated cyclodextrins have shown high selectivity to various racemates $[162,163]$. Several anionic cyclodextrins such as sulfobutylether $\beta$-cyclodextrin and $\beta$-cyclodextrin phosphate showed high enantioselectivity to numerous basic racemates as compared to natural species [164-166]. Such $\beta$-cyclodextrin derivatives are particularly successful in separating cationic analytes owing not only to the electrostatic interaction between the oppositely charged chiral selector and the solutes, but also owing to the large difference in the electrophoretic mobilities between free and complexed analytes.

On the other hand, cationic derivatives of $\beta$-cyclodextrin, like mono(6- $\beta$-aminoethylamino-6-deoxy)- $\beta$-cyclodextrin and 6A,6B-dimethylamino- $\beta$-cyclodextrin are more appropriate to separate anionic analytes. The problem is, that the cationic $\beta$-cyclodextrin selectors are not commercially available. The same holds for quaternary ammonium $\beta$-cyclodextrin [167].

As in other forensic and toxicological applications, sensitivity may be a problem in chiral separations. Obvious approaches, like tagging of the chiral analytes with a fluorescent tag may be useful. Also, detection at short wavelength can be a remedy. However when a strong absorbing chiral selector is employed for stereoselective analysis, such wavelengths are not useful. Thus, in order to avoid a decrease in sensitivity due to the absorption of the chiral selector (typically vancomycin) the so called partial filling technique is recommendable. In this case the background electrolyte containing the chiral selector filled only a part of the separation capillary up to the detectors' window keeping the window and the rest of the capillary free of the stereoselective compound. At $\mathrm{pH} 5-7$ vancomycin exhibits a positive charge and moves in the opposite way in analysis which precludes it to reach the detectors window. 
Additional modifications of such an approach, like using a coated capillary to (nearly) eliminate the endosmotic flow as well as to reduce adsorption of the chiral selector to the capillary wall can be applied as well. An example of acidic herbicides using vancomycin as chiral selector and partial filling technique is demonstrated in Fig. 22 [168].

\subsection{Micellar electrokinetic chromatography of proteins}

Micellar electrokinetic chromatography of proteins represents a new technique of separating proteins and their fragments which exploits the hydrophobic properties of these analytes. Proteins have provided significant challenges for separation by capillary electrophoresis because of their tendency to adsorb to the capillary wall through a variety of mechanisms. In principle it is possible to hinder these effects by (i) running the separations at extremely high $\mathrm{pH}$ at which the ionization of the free aminogroups is oppressed minimizing thereby the interaction with the capillary wall. Particularly with peptides this is a convenient way of handling the analysis. The advantage of this arrangement is the speed of separation and sufficient resolution power in a relatively wide range of $\mathrm{pH}$. The other possibility (ii) is to use extremely low $\mathrm{pHs}$, most frequently around 2.5 where the dissociation of the silanol groups of the inner capillary wall is hindered resulting consequently in nearly abolishing the capillary wall solute interactions. The third approach (iii) is to shield the capillary from its content by modifying its
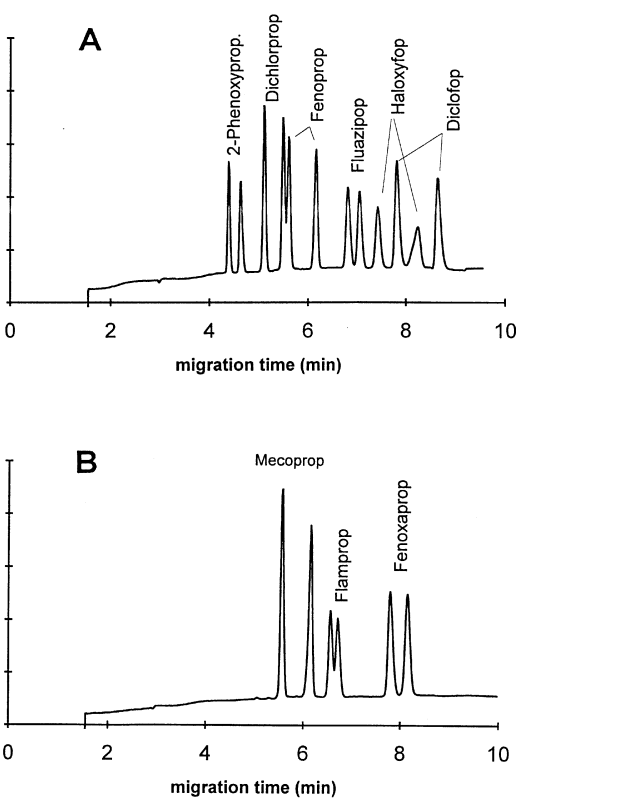

Fig. 22. Electropherograms of the enantiomeric separation of herbicides. A, 2-phenoxypropionic acid, dichlorprop, fenoprop, fluazifop, haloxyfop and diclofop; B, mecoprop, flamprop and fenoxaprop. $6 \mathrm{mM}$ of vancomycin partial filling at 150 psi.s; applied voltage $20 \mathrm{kV}(47 \mu \mathrm{A})$; analyte concentration was $10^{-4} \mathrm{M}$ with exception of fenoprop and diclofop $\left(5.10^{-5} \mathrm{M}\right)$ and 2-phenoxypropionic acid $\left(2.10^{-4} \mathrm{M}\right)$. With permission from Ref. [168]. 
surface by, e.g. polyacrlyamide. Another possibility is to fill, or better to add a polymeric constituent, typically polyvinylalcohol or hydroxymethyl cellulose to the background electrolyte by which approach not only the surface of the capillary is shielded from its content but the polymeric additive frequently exhibits molecular sieving properties allowing the analyst to separate individual proteins or protein fragments according to their molecular size. In specific cases, mainly with proteins exhibiting high degree of internal homogeneity it is possible by using separations in acid media to exploit the otherwise adverse sorption effects for separation: typically with e.g. collagen fragments the larger fragments exhibit much larger hydrophobic domains compared to the smaller ones and the separation occurs on the basis of equilibria between the sorbed and non-adsorbed molecules. It has to be emphasize that practically all separations run in acid buffers of $\mathrm{pH}$ around 2.5 are governed predominantly by electromigration because the endosmotic flow is extremely slow, particularly if the concentration of the background electrolyte is around $100 \mathrm{mmol} \mathrm{l}^{-1}$.

Protein capillary wall interactions in both bare silica and coated capillaries have been successfully minimized or eliminated through the use of ionic, zwitterionic or neutral surfactants. Being directed towards abolishing the protein-inner wall interactions none of the early reports investigated the possibility of achieving high resolution protein separations.

Although most proteins are too large to partition into the hydrophobic core of the micelles in micellar separations, proteins can associate with micelles through hydrophobic, hydrophilic and electrostatic mechanisms. Basically two types of surface active agents have been exploited recently for this types of separation, namely cetyltrimethylammonium bromide/chloride and sodium dodecyl sulphate. It is to be kept in mind that with systems exploiting celytrimethylammonium ions as micelle forming agents the whole system has to be run at reversed polarity, i.e. with anode at the detection and cathode at the injection end of the capillary. With the micellar systems the concentration of the micelle forming agent must be adequately high in order not only to create the micelles (supramicellar concentration) but to saturate the capillary wall as well. It is, perhaps, not surprising that micellar electrokinetic separations are particularly useful for proteins exhibiting high affinity to hydrophobic ligands like apolipoproteins. On the other hand this technique is also applicable for the separation of glycoproteins which frequently exhibit a large diversity owing to the difference of the glycosidic portion of the molecule. Usually in SDS mediated micellar separations analytes with the shortest migration times are those associated with the largest glycan structures. For a review see [169]).

Regarding forensic science micellar electrokinetic separations represent a powerful tool for analysing any protein samples no matter what the sample matrix is; typically this approach can be used not only for proteins in human and animal body but for food proteins as well. Another possibility of this approach is that proteins isolated by SDS slab gel electrophoresis can be transferred to the capillary and separated directly in the form of their SDS complexes: this is particularly important because in many cases the surfactant-protein complexes are in most cases very strong and are difficult to disrupt.

As any method also the electrokinetic micellar chromatography (electrophoresis) in the presence of endosmotic flow discussed above has also some disadvantages, the main 
being long migration times. The reason is that association with the micelle creates a strong charge of the micelle-protein adduct which makes it move rather swiftly to the injection end (anodic) of the capillary. By eliminating the endosmotic flow through polyacylamide coated capillary Strege and Lagu [169] were able to decrease protein separation time significantly while still preserving the selectivity of a mixture of five model proteins

An attractive alternative for micellar electrokinetic separation of proteins is the use of neutral or zwitterionic surfactants. These surface active agents in principle do not alter the net charge of analytes to which they are bound and they generally do not induce protein denaturation. So far such systems proved useful for the separation of peptides comprising ten to twenty amino acids; a further possibility how to increase the selectivity of these systems is to modify the partitioning mechanism between the protein/peptide analyte and the micelle by add in an organic modifier to the background electrolyte. Typically acetonitrile is used for this purpose.

\subsection{Nucleic acids and their fragments}

Capillary electrophoresis in uncrosslinked polymer solutions offers the possibility of fast and efficient separations of DNA and particularly its restriction fragments up to $23000 \mathrm{bp}$. A number of polymers have been used for this purpose; their common feature is that they produce viscous solutions in the background electrolytes used which ensures molecular sieving. The advantage of such solutions is that they are replaced with every single run and thus, on the contrary to capillaries filled with cross-linked gels, no problems with capillary clogging and losses in efficiency occur if the analysis is repeated many times.

Most of these polymers can be obtained or synthesized in a wide range of molecular mass and dissolved at various concentrations in the background electrolyte which allows to accommodate these systems with a large number of e.g. DNA species and fragments. The operative concentration depends on the characteristics of the polymer which should be employed above its overlap threshold concentration. Solutions of natural polysaccharides such as hydroxyethyl- [170-174], hydroxypropylmethyl- [175-179], methylcellulose [180,181], liquified agarose [182,183] have been used with varying degrees of success as have synthetic polymers like uncrosslinked acrylamide [184-186], polyvinylalcohol [187] and polyethylene oxide [188]. The fact that so many polymers have been tested in the pasts provides evidence that none of the sieving modifiers used is ideal and the analysts have to search for compromises.

The very first synthetic polymer used was polyacrylamide: the reason was that this polymer exhibits an unsurpassable sieving capacity and provides excellent separations of both single and double stranded DNAs. On the other hand there are drawbacks which limit the use of these polymers on a large scale. Perhaps the most obvious one is the high viscosity of polyacrylamide solutions which in turn depends on the high molecular mass of the constituting polymer chains [189]. The molecular mass of the polymer can be adjusted in the polymerization step by a number of ways $[184,190]$. One possibility is to carry out the polymerization in the presence of chain transfer agents such as isopropylalcohol [191], or by increasing the catalyst concentration [186]. In spite of the 
fact that the average molecular mass of the polymer is decreased through such operations, its viscosity still remains quite high. This in turn means that polymer concentrations higher than $6.5 \%$ can hardly be used. The other way is fractionation of the arising polymer: established techniques are used for this purpose (typically gel permeation, dialysis, fractional precipitation), however, this is from the analytical point of view a considerable complication.

For the purpose of DNA analysis generally, low viscosity polymers are used the reason is twofold, first, replacing the gel at the end of an analytical run is much shorter with low viscosity solutions, second the separations as such are shorter, because in less viscous polymers DNA molecules move more swiftly.

It is also true that the rheological properties of the gels preclude obtaining high reproducibility in DNA separations. In addition polyacrylamide gels are sensitive to hydrolytic cleavage in alkaline solutions [191], particularly at high temperatures hydrolysis of the amido linkage occurs, generating carboxyl residues in the matrix. In order to overcome these drawbacks, polymers obtained by radical polymerization of $N$-mono and disubstituted acrylamide derivatives were proposed [192]. Some idea about the efficiency of such polymers can be obtained from Fig. 23.

The sensitivity of the CE procedures by UV direct detection method $(260 \mathrm{~nm}$ for DNA) is relatively poor with a detection limit of a few $\mathrm{mg} \mathrm{ml}^{-1}$ of e.g. dsDNA sample [193] which is similar to the conventional slab gel analysis using ethidium bromide staining [193].

To increase the sensitivity limit it was proposed to use thiazole orange as an intercalator for laser-induced fluorescence of the separated samples (excitation $488 \mathrm{~nm}$ )

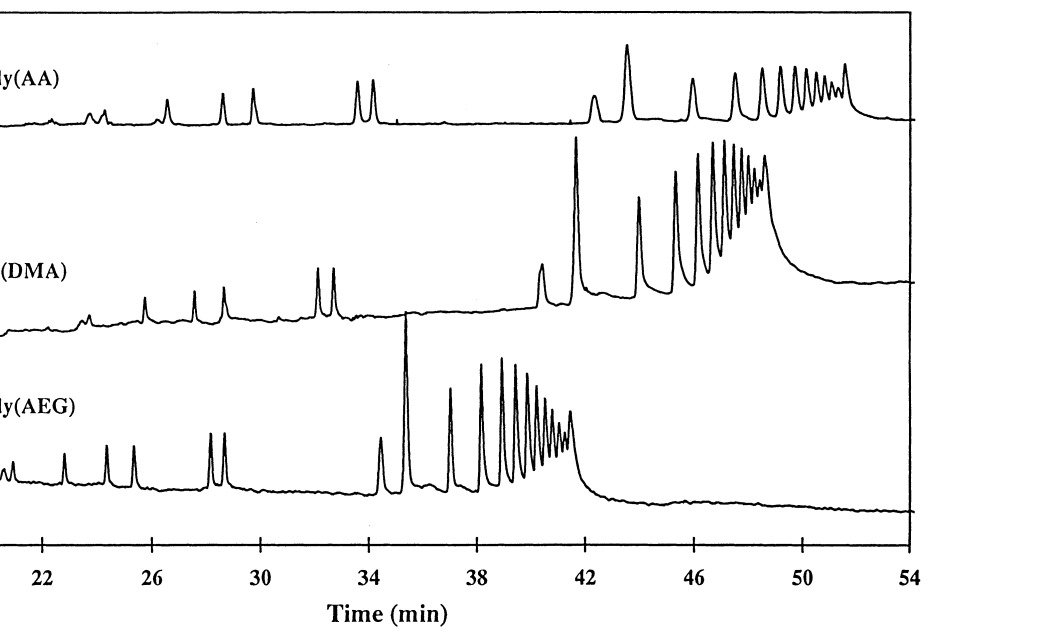

Fig. 23. CE separation of $1 \mathrm{~kb}$ ladder in various $7.5 \% \mathrm{w} / \mathrm{v}$ polymer solutions. Conditions, buffer $100 \mathrm{mM}$ TAPS-Tris, $2 \mathrm{mM}$ EDTA $\mathrm{pH}$ 8.5. Applied voltage $130 \mathrm{~V} \mathrm{~cm}^{-1}$. AA-acrylamide, DNA- $N, N$-dimethylacrylamide, AEG- $N$-(acryloylaminoethoxy)ethyl- $\beta$-D-glucopyranoside. With permission from Ref. [192]. 
[194]. The bound dye emisses with a much higher intensity compared to the unbound molecule and a red shift in the emission wavelengths can be observed (520 nm when bound, $580 \mathrm{~nm}$ when unbound) The experience obtained with this dye is quite plausible [195]. However other dyes were proposed as well; McCord et al. [196] reported on the application of a dye called YO-PRO-1, 1-(4-[3-methyl-2,3-dihydro(benzo-1,3-oxazole)2-methyidene-]-quinolinium-3-trimetylammonium propane diiodide. Another dye is the so called TO-PRO-3 which is structurally similar to the YO-PRO-1 except that instead of an oxazole ring it comprises a thiazole. The common denominator here is that the dyes used should be blue allowing the use of red light emitting lasers (excitation maxima with all the dyes used so far are in the range of 610-665 nm) [197]. It has to be noticed that while ethidium bromide or thiazole orange staining results in the presence of DNA in a blue shift of the emission maximum, the newly developed dyes exhibit just the opposite effect (red shift) [197]. The practice of staining is quite simple: the dye is usually added to the gel solution at a concentration of $0.05-1.0 \mathrm{mmol}^{-1}$. A typical example of separation is in Fig. 24.

Another area of problems in DNA analysis is related to the sequencing procedures and structure elucidation. Initially the gel medium and buffer systems used were identical with slab gel electrophoresis procedures. It was reported that the analysis of DNA fragments up to 700 bases can be carried out within 230 min with such conventional gels [198]. Despite this successful application, cross-liked polyacrylamide gels have become less popular due to gel inhomogeneity, bubble formation and short lifetime of the capillary and replaceable polymers are preferred today [199,200]. In addition to linear polyacrylamide, cellulose derivatives were found to be good sieving matrices for not only the standard version of capillary electrophoresis but for the microchip format as well [200]. A resolution limit of $450 \mathrm{bp}$ in $75 \mu \mathrm{m}$ capillaries at $200 \mathrm{~V} \mathrm{~cm}^{-1}$ was reported. Recently a temperature-sensitive polymer matrix for both capillary and slab gel electrophoresis was introduced which allows sequencing of fragments up to $150 \mathrm{bp}$ with a single base resolution [201].

One important aspect of DNA sequencing is that the sequencing analysis should allow for as long reads as possible as this reduces the needs for repeated cloning of short fragments derived from the longer ones which is quite a time consuming process. At present there has been only occasional success in separating DNA up to $1000 \mathrm{bp}$ in a sequencing run using linear polymer solutions in capillary gel electrophoresis [202]. The Yeung's group reported the use of a replaceable poly(oxyethylene) linear polymer and quite recently they reported its successful application to sequencing up to $1000 \mathrm{bp}$ [203-205]. The sequencing run using the poly(oxyethylene) matrix is shown in Fig. 25.

New equipment and a new procedures have been recently published regarding genetic mapping and DNA sequencing [206]. The so-called capillary array electrophoresis in which 48-96 capillaries are run simultaneously offered good results in practice. In short using multiplex polymerase chain reaction and multicolor dye labeling strategies allows to generate DNA profiles containing 18-14 genotypes per sample. By using 4-color fluorescence detection and these multiplex PCR strategies, a capillary array electrophoresis system has the capacity of generating up to $5.5 \times 10^{6}$ genotypes per year. Indeed capillary array electrophoresis offers much faster resolution of DNA and sample 


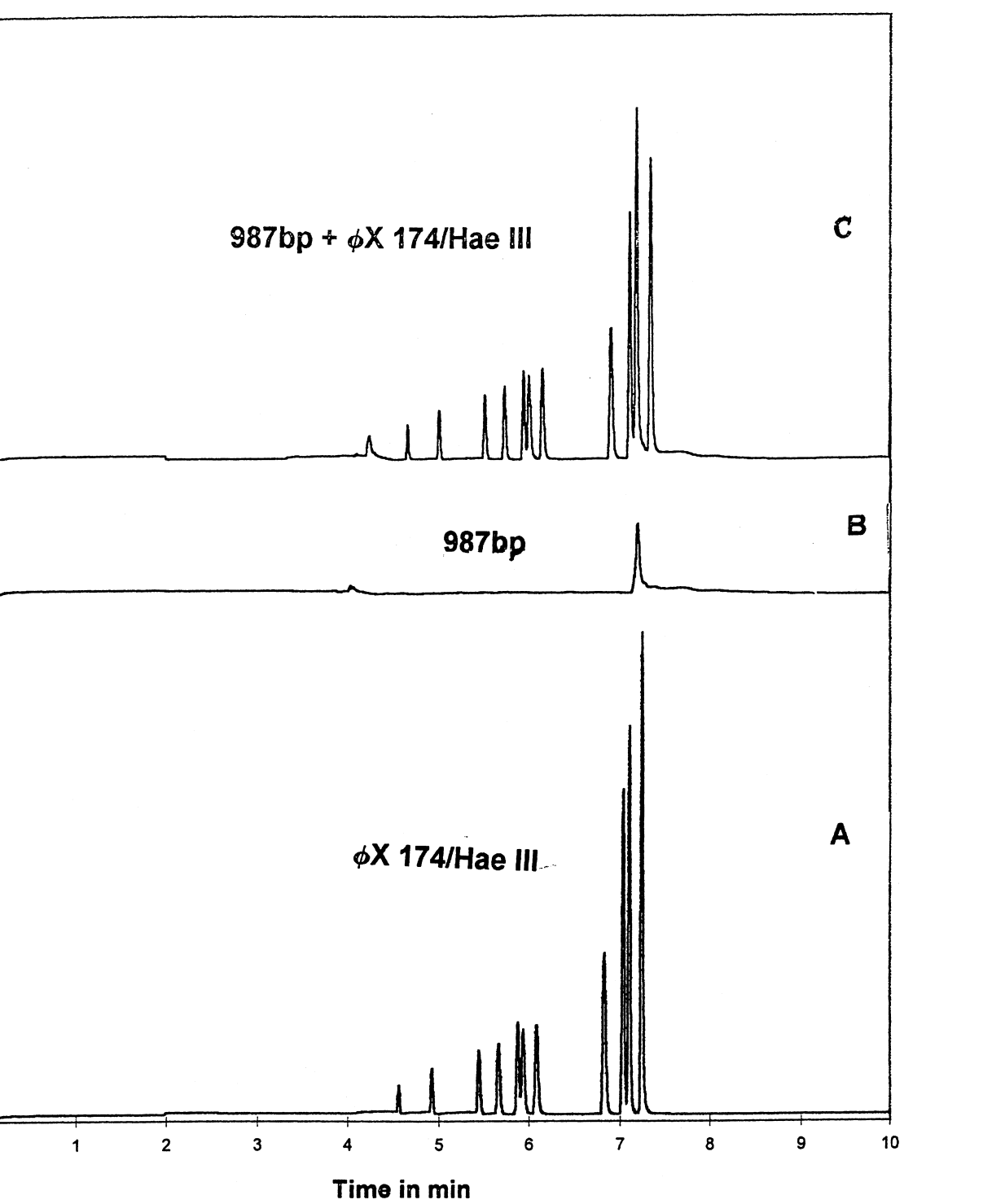

Fig. 24. Electropherograms of: A, fX 174/Hae III restriction fragments; B, a PCR product of $970 \mathrm{bp}$; C, fX 174/Hae III restriction fragments and a PCR product of $970 \mathrm{bp}$. in 3\% linear polyacrylamide with $0.1 \mathrm{mM}$ TO-PRO 3, $75 \mathrm{~mm} \times 27 \mathrm{~cm}$ coated capillary; $8 \mathrm{kV} / 24$; detection $635 \mathrm{~nm}$ excitation, $670 \mathrm{~nm}$ emission. With permission from Ref. [197].

processing than conventional systems. The equipment is to our best knowledge not commercially available and also applications [207] for which it has been used exploits the prototype reported in ref. [206]. 

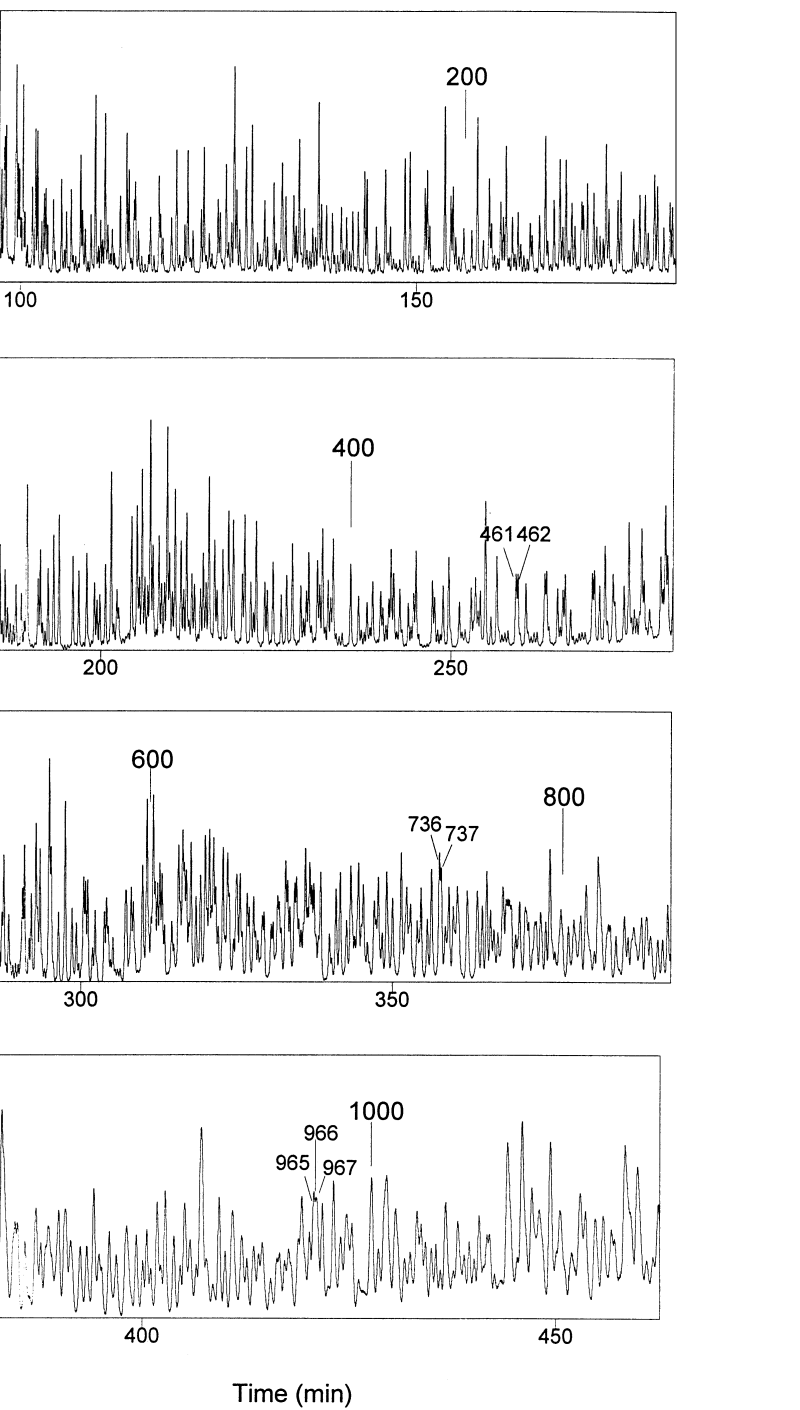

Fig. 25. Electropherograms of PGEM/U DNA sequencing sample up to $1000 \mathrm{bp}$ (counting from the primer peak). Conditions: $1 \times \mathrm{TBE}$ buffer with $3.5 \mathrm{M}$ urea, $75 \mathrm{~V} \mathrm{~cm}^{-1}$ field strength, gel concentrations at $1.5 \% M_{\mathrm{r}}$ 8000000 PEO and 1.4\% $M_{\mathrm{r}} 600000 \mathrm{PEO}, 70 \mathrm{~cm}$ effective length, $30 \mathrm{~s}$ injection at running voltage. From Ref. [205] with permission.

\section{Conclusions}

In the past five years when instrumentation for capillary electrophoresis became standardized and commercially available, a plethora of the most diverse applications to the most diversified categories of compounds appeared. Though direct applications to the 
forensic science are still limited, it is believed that it is only a matter of time when this area will be penetrated by capillary electrodriven separations as well. In this article the recently developed methods for sample treatment, sensitivity enhancement, hyphenation and newly developed detection procedures are reviewed along with selected types of applications referring mainly to chiral separations and separation of biopolymers.

\section{Acknowledgements}

This work was supported by the Grant Agency of the Czech Republic, grant No. 303/96/K128.

\section{References}

[1] S. Terabe, K. Otsuka, K. Ichikawa, A. Tsuchiya, T. Ando, Anal. Chem. 56 (1984) 111.

[2] Z. Deyl, F. Tagliaro, I. Mikšík, J. Chromatogr. B 656 (1994) 3.

[3] F. Tagliaro, F.P. Smith, Z. de Battisti, G. Manetto, M. Marigo, J. Chromatogr. B 689 (1997) 261.

[4] M.V. Novotny, J. Chromatogr. B 689 (1997) 55.

[5] N. Matsubara, S. Terabe, Methods Enzymol. 270 (1996) 678.

[6] I.E. Valkó, H. Sirén, M.-L. Riekkola, LC-GC Int. 10 (1997) 190.

[7] A.T. Balchunas, M.J. Sepaniak, Anal. Chem. 59 (1987) 1466.

[8] J. Vindvogel, P. Sandra, Anal. Chem. 63 (1991) 1530.

[9] P. Lukkari, H. Vuorela, M.L. Riekkola, J. Chromatogr. A 655 (1993) 317.

[10] C. Stathakis, P.L. Walburton, R.M. Cassidy, J. Chromatogr. A 659 (1994) 443.

[11] K. Otsuka, M. Higashimori, R. Koike, K. Karahuha, Y. Okada, S. Terabe, Electrophoresis 15 (1994) 1280.

[12] S. Terabe, B.L. Karger, K. Hosoya, N. Tanaka, J. Chromatogr. 516 (1990) 23.

[13] Y.F. Yik, C.P. Ong, S.B. Khoo, H.K. Lee, S.F. Li, J. Chromatogr. 589 (1992) 333.

[14] S. Terabe, Y. Miyashita, Y. Ishishama, O. Shibata, J. Chromatogr. 636 (1993) 47.

[15] C.L. Cooper, M.J. Sepaniak, Anal. Chem. 66 (1994) 147.

[16] N. Tanaka, K. Nakagawa, H. Iwasaki, K. Hosoya, K. Kimata, T. Araki, D. Patterson Jr., J. Chromatogr. A 781 (1997) 139.

[17] C.P. Palmer, H.M. McNair, J. Microcol. Separ. 4 (1992) 509.

[18] C.P. Palmer, M.Y. Khaled, H.M. McNair, J. High Res. Chromatogr. 15 (1992) 756.

[19] S. Terabe, T. Isemura, Anal. Chem. 62 (1990) 650.

[20] H. Ozaki, S. Terabe, A. Ichikara, J. Chromatogr. A 680 (1994) 117.

[21] C.P. Palmer, S. Terabe, J. Microcolumn Separ. 8 (1996) 115.

[22] J. Wang, I.M. Warner, Anal. Chem. 66 (1994) 3773.

[23] W. Schutzner, S. Fanali, A. Rizzi, E. Kenndler, J. Chromatogr. 639 (1993) 375.

[24] S. Terabe, H. Ozaki, Y. Tanaka, J. Chin. Chem. Soc. 41 (1994) 251.

[25] H. Ozaki, A. Ichikara, S. Terabe, J. Chromatogr. A 709 (1995) 3.

[26] H. Ozaki, N. Itou, S. Terabe, Y. Takeda, M. Sakairi, H. Koizumi, J. Chromatogr. A 716 (1995) 69.

[27] S. Yang, J.G. Baumgartner, M.G. Khaledi, J. Chromatogr. A 738 (1996) 265.

[28] N. Tanaka, T. Tanigawa, K. Hosoya, K. Kimata, T. Araki and S. Terabe, Chem. Lett., (1992) 959.

[29] N. Tanaka, T. Tuskutome, T. Tanigawa, K. Hosoya, K. Kimata, T. Araki, K.K. Unger, J. Chromatogr. A 699 (1995) 331.

[30] L. Vomastová, I. Mikšík, Z. Deyl, J. Chromatogr. B 681 (1996) 107. 
[31] G.A. Valbuena, L.V. Rao, J.R. Petersen, A.O. Okorodudu, M.G. Bissell, A.A. Mohammad, J. Chromatogr. A 781 (1997) 467.

[32] M.A. Schwarz, K. Raith, H.H. Rüttinger, G. Dongowski, R.H.H. Neubert, J. Chromatogr. A 781 (1997) 377.

[33] O. Schmitz, S. Gäb, J. Chromatogr. A 781 (1997) 215.

[34] S. Kiessig, C. Vogt, J. Chromatogr. A 781 (1997) 475.

[35] S. Takeda, S.-I. Wakida, M. Yamane, K. Higashi, S. Terabe, J. Chromatogr. A 781 (1997) 11.

[36] H.-T. Chang, E.S. Yeung, J. Chromatogr. 608 (1992) 65.

[37] A.T. Blachunas, M.J. Sepaniak, Anal. Chem. 60 (1988) 617.

[38] F. Foret, S. Fanelli, P. Boèek, J. Chromatogr. 516 (1990) 219.

[39] T. Tsuda, Anal. Chem. 64 (1992) 396.

[40] P. Boèek, M. Demi, J. Pospíchal, J. Sudor, J. Chromatogr. 470 (1989) 309.

[41] V. Purghart, D.E. Games, J. Chromatogr. 605 (1992) 139.

[42] C.-W. Chang, E.S. Yeung, Anal. Chem. 64 (1992) 502.

[43] P. Boček, M. Demi, J. Pospíchal, J. Chromatogr. 500 (1990) 673.

[44] W.E. Rae, J.E. Wong, C.A. Lucy, J. Chromatogr. A 781 (1997) 3.

[45] C.S. Lee, W.C. Blanchard, C.T. Wu, Anal. Chem. 62 (1990) 1550.

[46] C.S. Lee, D. McManigill, C.T. Wu, B. Patel, Anal. Chem. 63 (1991) 1519.

[47] M.A. Hayes, A.W. Ewing, Anal. Chem. 64 (1992) 512.

[48] M.A. Hayes, I. Kheterpal, A.W. Ewing, Anal. Chem. 65 (1993) 27.

[49] C.T. Culbertson, J.W. Jorgenson, Anal. Chem. 66 (1994) 955.

[50] N. Burggraf, A. Manz, C.S. Effenhauser, E. Verpoorte, N.F. de Rooij, H.M. Widmer, J. High Res. Chromatogr. 16 (1993) 594.

[51] F. von Heeren, E. Verpoorte, A. Manz, W. Thormann, Anal. Chem. 68 (1996) 2044.

[52] Joong-Gill Choi, Rajeev Dadoo, R.N. Zare, J. Chromatogr. A, in press

[53] D.L. Mould, R.L.M. Synge, Biochem. J. 58 (1954) 571.

[54] D.L. Mould, R.L.M. Synge, Analyst 77 (1952) 964.

[55] J.W. Jorgenson, K.D. Lukacs, J. Chromatogr. 218 (1981) 209.

[56] H. Rebscher, V. Pyell, J. Chromatogr. 737 (1996) 171.

[57] J.H. Knox, I.H. Grant, Chromatographia 24 (1987) 4014.

[58] H. Yamamoto, J. Bauman, F. Erni, J. Chromatogr. 593 (1992) 313.

[59] N.W. Smith, M.B. Evans, Chromatographia 38 (1994) 649.

[60] G. Choudhary, Cs. Horvath, J. Chromatogr. A 781 (1997) 161.

[61] R.J. Boughtflower, T. Underwood, J. Maddin, Chromatographia 41 (1995) 398.

[62] B. Behnke, E. Bayer, J. Chromatogr. A 680 (1994) 93.

[63] C. Yan, R. Dadoo, R.N. Zare, D.J. Rakestran, D.S. Anex, Anal. Chem. 68 (1996) 2726.

[64] M.M. Dittmann, G.P. Rozing, J. Chromatogr. A 744 (1996) 63.

[65] D.N. Heiger, M. Herold, R. Grimm, Applications of Hewlett-Packard 3D Capillary Electrophoresis System, Hewlett Packard Company, Waldbronn, Germany 1992.

[66] R.L. Chien, D.S. Burgi, Anal. Chem. 64 (1992) 489A.

[67] D.S. Burgi, R.L. Chien, J. Microcolumn Separ. 3 (1991) 19.

[68] D.S. Burgi, R.L. Chien, Anal. Chem. 63 (1991) 2042.

[69] R.L. Chien, D.S. Burgi, J. Chromatogr. 559 (1991) 141.

[70] R.L. Chien, D.S. Burgi, J. Chromatogr. 559 (1991) 153.

[71] R.L. Chien, J.C. Helmer, Anal. Chem. 63 (1991) 1354.

[72] R.L. Chien, D.S. Burgi, Anal. Chem. 64 (1992) 1046.

[73] K.R. Nielsen, J.P. Foley, J. Chromatogr. A 686 (1994) 283.

[74] Z. Liu, P. Sam, S.R. Sirimanne, P.C. McClure, J. Grainger, D.G. Patterson, J. Chromatogr. A 673 (1994) 125.

[75] D.S. Burgi, R.L. Chien, Anal. Chem. 63 (1991) 2042.

[76] Z.K. Shihabi, J. Chromatogr. A 744 (1996) 231.

[77] M.A. Friedberg, M. Hinsdale, Z.K. Shihabi, J. Chromatogr. A 781 (1997) 35.

[78] J.P. Quirino, S. Terabe, J. Chromatogr. A 781 (1997) 119. 
[79] B.J. Harmon, D.H. Patterson, F.E. Regnier, Anal. Chem. 65 (1993) 2655.

[80] Ä. Emmer, J. Roeraade, J. Chromatogr. A 662 (1994) 375.

[81] W. Nashabeh, Z. El Rassi, J. Chromatogr. 596 (1992) 251.

[82] L.N. Amankawa, W.G. Kuhr, Anal. Chem. 64 (1992) 1610.

[83] N. Kaneki, Y. Xu, A. Kumari, H.B. Halsall, W.R. Heineman, P.T. Kissinger, Anal. Chem. 287 (1994) 253.

[84] A.J. Tomlinson, N.A. Guzman, S. Naylor, J. Cap. Electrophor. 2 (1995) 247.

[85] N.A. Guzman, M. A Trebilcock, J.P. Advis, J. Liq. Chromatogr. 14 (1991) 997.

[86] M.E. Swartz, M. Merion, J. Chromatogr. 632 (1993) 209.

[87] A.J. Tomlinson, S. Naylor, J. Liq. Chromatogr. 18 (1995) 3591.

[88] L. Bao, P.K. Dasgupta, Anal. Chem. 64 (1992) 991.

[89] M.M. Dittmann, K. Wienand, F. Bek, G.P. Rozing, LC-GC 13 (1995) 800.

[90] L.G. Rashkovetsky, E.V. Lyubarskaya, F. Foret, D.E. Hughes, B.L. Karger, J. Chromatogr. A 781 (1997) 197.

[91] B.-I. Haukanes, C. Kvam, Biotechnology 11 (1993) 60.

[92] P.D. Rye, Bio/Technology 14 (1996) 155.

[93] M.J. Suh, Y.S. Kim, Y.S. Yoo, J. Chromatogr. A 781 (1997) 263.

[94] N.H.H. Heegaard, in: K. Standing (Ed.), New methods for the study of molecular aggregates, Kluwer Academic Publishers, Dordrecht, 1997.

[95] Y.-H. Chu, L.Z. Avila, J. Gao, G.M. Whitesides, Acc. Chem. Res. 28 (1995) 461.

[96] Y.-H. Chu, L.Z. Avila, H.A. Biebuyck, G.M. Whitesides, J. Med. Chem. 35 (1992) 2915.

[97] N.H.H. Heegaard, F.A. Robey, Anal. Chem. 64 (1992) 2479.

[98] P.D. Grossman, J.C. Colburn, H.K. Lauer, Anal. Biochem. 179 (1989) 28.

[99] P.D. Grossman, J.C. Colburn, H.K. Lauer, R.G. Nielsen, R.M. Riggin, G.S. Sittampalam, E.C. Rickard, Anal. Chem. 61 (1989) 1186.

[100] N.H.H. Heegaard, B.E. Hansen, A. Svejgaard, L.H. Fugger, J. Chromatogr. A 781 (1997) 91.

[101] D.J. Harrison, A. Manz, H. Lüdi, M.H. Widmer, Anal. Chem. 64 (1992) 1926.

[102] A. Manz, D.J. Harrison, E.M.J. Veerporte, C. Fettinger, A. Paulus, H. Lüdi, H.M.J. Widmer, J. Chromatogr. 593 (1992) 253.

[103] K. Seiler, D.J. Harrison, A. Manz, Anal. Chem. 65 (1993) 1481.

[104] D.J. Harrison, K. Fleni, K. Seiler, Z. Fan, C.S. Effenhauser, A. Manz, Science 261 (1993) 895.

[105] S.C. Jacobson, R. Hergenröden, L.B. Koutny, R.J. Warmack, J. Ramsey, Anal. Chem. 66 (1994) 1107.

[106] S.C. Jacobson, R. Hergenröder, L.B. Koutny, J.M. Ramsey, Anal. Chem. 66 (1994) 1114.

[107] C.S. Effenhauser, A. Manz, Int. Laboratory 24(9) (1994) 10.

[108] I. Rodriquez, Y. Zhang, H.K. Lee, S.F.Y. Li, J. Chromatogr. A 781 (1997) 287.

[109] R.D. Smith, H.R. Udseth, C.J. Barinaga, C.G. Edmonds, J. Chromatogr. 559 (1991) 197.

[110] M. Dole, Preprints, Int. Symp. Macromol. Chem. 6 (1966) 132.

[111] M. Dole, L.L. Mack, R.L. Hines, R.C. Mobley, L.D. Ferguson, M.B. Alice, J. Chem. Phys. 49 (1968) 2240.

[112] J.V. Iribarne, B.A. Thomson, J. Chem. Phys. 64 (1976) 2287.

[113] M. Yamashita, J.B. Fenn, J. Phys. Chem. 88 (1984) 3351.

[114] M. Yamashita, J.B. Fenn, J. Phys. Chem. 88 (1984) 4671.

[115] L. Fang, R. Zhang, E.R. Williams, R.N. Zare, Anal. Chem. 66 (1994) 3696.

[116] D.C. Muddiman, A.L. Rockwood, Q. Gao, J.C. Severs, R.D. Smith, Anal. Chem. 67 (1995) 4371.

[117] X. Li, L. Hogwei, D. Lubman, Proceedings of the 43rd ASMS Conference on Mass Spectrometry and Allied Topics, Atlanta, GA, 1995; TPB089.

[118] J.F. Banks, T. Dresch, Anal. Chem. 68 (1996) 1480.

[119] J.-T. Wu, M.G. Qian, M.X. Li, L. Liu, D.M. Lubman, Anal. Chem. 68 (1996) 3388.

[120] A. Verentchikov, F. Hsieh, S. Gabeler, S. Martin, M. Vestal, Proceedings of the 44th ASMS Conference on Mass Spectrometry and Allied Topics, Portland, OR, 1996, p. 285.

[121] J.-T. Wu, P. Huang, M.X. Li, M.G. Qian, D.M. Lubman, Anal. Chem. 69 (1997) 320.

[122] I.M. Lazar, E.D. Lewis, A.L. Rockwood, M.L. Lee, J Chromatogr. A, 791 (1997) 269.

[123] A.P. Bruins, T.R. Covey, J.D. Henion, Anal. Chem. 59 (1987) 2642.

[124] J.-Y. Zhao, P. Thiebault, T. Tazawa, M.A. Quilliam, J. Chromatogr. A 781 (1997) 555. 
[125] F. Ariese, G.J. Small, R. Jankowiak, Carcinogenesis 17 (1996) 829.

[126] M. Suh, F. Ariese, G.J. Small, R. Jankowiak, T.-M. Liu, N.E. Geacintov, Biophys. Chem. 56 (1995) 2561.

[127] R. Jankowiak, D. Zamzow, W. Ding, G.J. Small, Anal. Chem. 68 (1996) 2549.

[128] D. Zamzow, G.J. Small, R. Jankowiak, Mol. Cryst. Liq. Cryst. 291 (1996) 155.

[129] K.M. Li, R. Todorovic, E.G. Rogan, E.L. Cavalieri, F. Ariese, M. Suh, R. Jankowiak, G.J. Small, Biochemistry 34 (1995) 8043.

[130] E.G. Rogan, P.D. Devanesan, N. RamaKrishna, S. Higginbotham, N.S. Padmavathi, K. Chapman, E.L. Cavalieri, H. Jeong, R. Jankowiak, G.J. Small, Chem. Res. Toxicol. 6 (1993) 356.

[131] P.D. Devanesan, N. RamaKrishna, N.S. Padmavathi, S. Higginbotham, E.G. Rogan, E.L. Cavalieri, G.A. Marsh, R. Jankowiak, G.J. Small, Chem. Res. Toxicol. 6 (1993) 364.

[132] M. Suh, F. Ariese, G.J. Small, R. Jankowiak, A. Hewer, D.H. Phillips, Carcinogenesis 16 (1995) 2561.

[133] N. Milanovich, M. Shu, J.M. Hayes, G.J. Smal, Biospectroscopy 2 (1996) 125.

[134] J. Wolf, K-Y. Law, A.B. Myers, J. Phys. Chem. 100 (1996) 11870.

[135] R.A. Avarmaa, K.K. Rebane, Spectrochim. Acta 41A (1985) 1365.

[136] H. Koloczek, J. Fidy, J.M. Vanderkooi, J. Chem. Phys. 87 (1987) 4388.

[137] P.J. Angiolillo, J.S. Leigth, J.M. Vanderkooi, Photochem. Photobiol. 63 (1982) 133.

[138] I. Renge, K. Mauring, R. Avarmaa, J. Lumin. 37 (1987) 207.

[139] D. Zamzow, C.-H. Lin, G.J. Small, R. Jankowiak, J. Chromatogr. A 781 (1997) 73.

[140] H. Wittrisch, S. Conradi, E. Rohde, J. Vogt, C. Vogt, J. Chromatogr. A 781 (1997) 407.

[141] C. Vogt, J. Vogt, A. Becker, E. Rohde, J. Chromatogr. A 781 (1997) 391.

[142] A. Dobashi, M. Hamada, Y. Dobashi, J. Yamaguchi, Anal. Chem. 67 (1995) 3011.

[143] S. Terabe, K. Otsuka, H. Nishi, J. Chromatogr. A 666 (1995) 295.

[144] M.M. Rogan, K.D. Altria, D.M. Goodall, Chirality 6 (1994) 25.

[145] R. Vespalec, P. Bocek, Electrophoresis 15 (1994) 755.

[146] M.W.F. Nielen, Anal. Chem. 65 (1993) 885.

[147] R.J. Taft, D.O. Thompson, V.J. Stella, J.F. Stobaugh, Anal. Chem. 66 (1994) 4013.

[148] K.H. Gahm, A.M. Stalcup, Anal. Chem. 67 (1995) 19.

[149] M.G. Schmid, G. Gubitz, Enantiomer 1 (1996) 23.

[150] D.W. Armstrong, K. Rundlett, G.L. Reid III, Anal. Chem. 66 (1994) 1690.

[151] K.L. Rundlett, D.W. Armstrong, Anal. Chem. 67 (1995) 2088.

[152] W. Schutzner, S. Fanali, A. Rizzi, E. Kendler, Anal. Chem. 67 (1995) 3866.

[153] H. Nishi, K. Nakamura, H. Nakai, T. Sato, Anal. Chem. 67 (1995) 2334.

[154] R. Kuhn, F. Erni, T. Bereuter, J. Hausler, Anal. Chem. 64 (1992) 2815.

[155] R. Kuhn, F. Stoecklin, F. Erni, Chromatographia 33 (1992) 32.

[156] R. Kuhn, J. Wagner, Y. Walbroehl, T. Bereuter, Electrophoresis 15 (1994) 828.

[157] Y. Walbroehl, J. Wagner, J. Chromatogr. A 680 (1994) 253.

[158] Y. Walbroehl, J. Wagner, J. Chromatogr. A 685 (1994) 321.

[159] E. Hohne, G.J. Krauss, G. Gubitz, J. High Res. Chromatogr. 15 (1992) 698.

[160] S. Li, D.K. Lloyd, Anal. Chem. 65 (1993) 3684.

[161] W.X. Huang, H. Xu, S.D. Fazio, R.V. Vivilecchia, J. Chromatogr. B 695 (1997) 157.

[162] H. Nishi, S. Terabe, J. Chromatogr. A 694 (1995) 245.

[163] S. Fanali, J. Chromatogr. A 735 (1996) 77.

[164] T. Schmitt, H. Engelhardt, Chromatographia 37 (1993) 475.

[165] A.M. Stalcup, K.H. Gahm, Anal. Chem. 68 (1996) 1360.

[166] Y. Tanaka, M. Yanagawa, S. Terabe, J. High Res. Chromatogr. 19 (1996) 421.

[167] Y. Tanaka, S. Terabe, J. Chromatogr. A 781 (1997) 151.

[168] C. Desiderio, C.M. Polcaro, P. Padiglioni, S. Fanali, J. Chromatogr. A 781 (1997) 503.

[169] M.A. Strege, A.L. Lagu, J. Chromatogr. A 780 (1997) 285.

[170] A.E. Barron, D.S. Soane, H.W. Blanch, J. Chromatogr. A 652 (1993) 3.

[171] P.D. Grossman, D.S. Soane, J. Chromatogr. A 559 (1991) 257.

[172] B.R. McCord, J.M. Jung, E.A. Holleran, J. Liq. Chromatogr. 16 (1993) 1963.

[173] H. Zhu, S.M. Clark, S.C. Benson, H.S. Rye, A.N. Glazer, R.A. Mathies, Anal. Chem. 66 (1994) 941. 
[174] J.M. Butler, B.R. McCord, J.M. Jung, M.R. Wilson, B. Budowle, R.O. Allen, J. Chromatogr. A 658 (1994) 71.

[175] Y. Baba, N. Ishimaru, K. Samata, M. Tsuhako, J. Chromatogr. A 653 (1993) 329.

[176] H.E. Schwartz, K. Ulfelder, F.J. Sunzeri, M.P. Buscll, R.G. Brownlee, J. Chromatogr. A 559 (1991) 267.

[177] J. Cheng, T. Kasuga, K.R. Mitchelson, E.R.T. Lightly, N.D. Watson, W.J. Martin, D. Atkinson, J. Chromatogr. A 677 (1994) 169.

[178] Y. Kim, M.D. Morris, Anal. Chem. 66 (1994) 1168.

[179] J.M. Butler, B.R. McCord, J.M. Jung, R.O. Allen, BioTechniques 17 (1994) 4.

[180] D.M. McGregor, E.S. Yeung, J. Chromatogr. A 680 (1994) 491.

[181] K. Ueno, E.S. Yeung, Anal. Chem. 66 (1994) 1424.

[182] P. Bocek, A. Chrambach, Electrophoresis 12 (1991) 1059.

[183] A. Charambach, A. Aldroubi, Electrophoresis 14 (1993) 18.

[184] P.D. Grossman, J. Chromatogr. A 663 (1994) 219.

[185] C. Gelfi, A. Orsi, F. Leoncini, P.G. Righetti, J. Chromatogr. A 689 (1995) 97.

[186] M.C. Ruiz-Martinez, J. Berka, A. Belenkii, F. Foret, A.W. Miller, B.L. Karger, Anal. Chem. 65 (1993) 281.

[187] V. Dolnik, M. Novotny, J. Microcol. Sep. 4 (1992) 515.

[188] E.N. Fung, E.S. Yeung, Anal. Chem. 67 (1995) 1913.

[189] M. Chiari, M. Nesi, P.G. Righetti, J. Chromatogr. A 652 (1993) 31.

[190] Odian, Principles of Polymerization, Third Edition, John Wiley, New York, 1991.

[191] M. Chiari, C. Micheletti, M. Nesi, M. Fazio, P.G. Righetti, Electrophoresis 15 (1994) 177.

[192] M. Chiari, S. Riva, A. Gelain, A. Vitale, E. Turati, J. Chromatogr. A 781 (1997) 347.

[193] T. Maniatis, E.F. Fritsh, J. Sambrook, Molecular cloning: A laboratory manual, 2nd edition, Cold Spring Harbor Laboratory, Cold Spring Harbor, N.Y., 1989.

[194] H.E. Schwartz, K.J. Ulfelder, Anal. Chem. 64 (1992) 1737.

[195] H. Zhu, M.S. Clark, S.C. Benson, H.S. Rye, R.A. Mathies, Anal. Chem. 66 (1994) 1941.

[196] B.R. McCord, D.L. McClure, J.M. Jung, J. Chromatogr. 652 (1993) 75.

[197] S. Rampal, M.-S. Liu, F.-T.A. Chen, J. Chromatogr. A 781 (1997) 357.

[198] M. Kahamori, H. Kambara, Electrophoresis 17 (1966) 1476.

[199] X.C. Huang, M.A. Quesada, R.A. Mathies, Anal. Chem. 64 (1992) 967.

[200] A.T. Woley, R.A. Mathies, Anal. Chem. 67 (1995) 3637.

[201] A.P. Sassi, A. Barron, M.G. Alonso-Amigo, D.Y. Hion, J.S. Yu, D.S. Soane, H.H. Hoopoer, Electrophoresis 17 (1996) 1460.

[202] E. Carrilho, M.C. Ruiz-Martinez, J. Berka, I. Smirnov, W. Goetzinger, A.W. Miller, D. Brady, B.L. Karger, Anal. Chem. 68 (1996) 6601.

[203] E.N. Tung, E.S. Yeung, Anal. Chem. 67 (1995) 1913.

[204] H. Chang, E.S. Yeung, J. Chromatogr. B 669 (1995) 113.

[205] Y. Kim, E.S. Yeung, J. Chromatogr. A 781 (1997) 315.

[206] J. Bashkin, D. Roach, J. Leong, D. Barker, R.J. Johnson, Capillary Electrophoresis 3 (1996) 60.

[207] E.S. Mansfield, M. Vainer, D.W. Harris, P. Gasparini, X. Estivill, S. Surrey, P. Fortina, J. Chromatogr. A 781 (1997) 295.

[208] D. Nedelkov, A.L. Bieber, J. Chromatogr. A 781 (1997) 429. 